This item was submitted to Loughborough's Research Repository by the author.

Items in Figshare are protected by copyright, with all rights reserved, unless otherwise indicated.

\title{
Fabrication and characterisation of 3D complex hydroxyapatite scaffolds with hierarchical porosity of different features for optimal bioactive performance
}

PLEASE CITE THE PUBLISHED VERSION

http://dx.doi.org/10.1016/j.ceramint.2016.09.160

\section{PUBLISHER}

(c) Elsevier

\section{VERSION}

AM (Accepted Manuscript)

\section{PUBLISHER STATEMENT}

This work is made available according to the conditions of the Creative Commons Attribution-NonCommercialNoDerivatives 4.0 International (CC BY-NC-ND 4.0) licence. Full details of this licence are available at: https://creativecommons.org/licenses/by-nc-nd/4.0/

\section{LICENCE}

CC BY-NC-ND 4.0

\section{REPOSITORY RECORD}

Chen, Zhichao, Xianglin Zhang, Yang Yang, Kui Zhou, Nicholas M. Wragg, Yang Liu, Mark P. Lewis, and Changqing Liu. 2019. "Fabrication and Characterisation of 3D Complex Hydroxyapatite Scaffolds with Hierarchical Porosity of Different Features for Optimal Bioactive Performance". figshare. https://hdl.handle.net/2134/22919. 


\section{Author's Accepted Manuscript}

Fabrication and characterisation of 3D complex hydroxyapatite scaffolds with hierarchical porosity of different features for optimal bioactive performance

Zhichao Chen, Xianglin Zhang, Yang Yang, Kui Zhou, Nicholas Wragg, Yang Liu, Mark Lewis, Changqing Liu

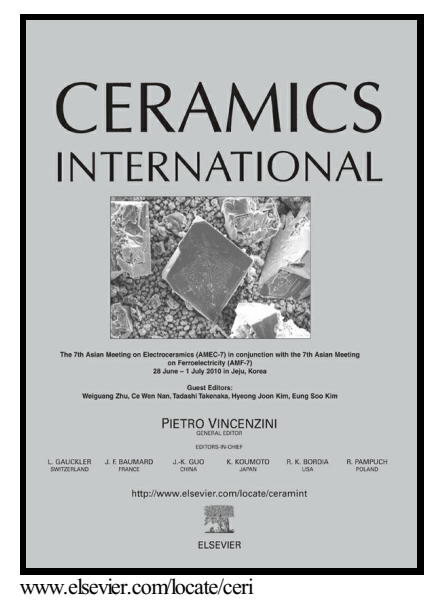

PII: $\quad$ S0272-8842(16)31691-1

DOI: $\quad$ http://dx.doi.org/10.1016/j.ceramint.2016.09.160

Reference: CERI13820

To appear in: Ceramics International

Received date: 11 August 2016

Revised date: 20 September 2016

Accepted date: 22 September 2016

Cite this article as: Zhichao Chen, Xianglin Zhang, Yang Yang, Kui Zhou Nicholas Wragg, Yang Liu, Mark Lewis and Changqing Liu, Fabrication anc characterisation of 3D complex hydroxyapatite scaffolds with hierarchica porosity of different features for optimal bioactive performance, Ceramic International, http://dx.doi.org/10.1016/j.ceramint.2016.09.160

This is a PDF file of an unedited manuscript that has been accepted fo publication. As a service to our customers we are providing this early version o the manuscript. The manuscript will undergo copyediting, typesetting, an review of the resulting galley proof before it is published in its final citable form Please note that during the production process errors may be discovered whic could affect the content, and all legal disclaimers that apply to the journal pertain 


\title{
Fabrication and characterisation of 3D complex hydroxyapatite scaffolds with hierarchical porosity of different features for optimal bioactive performance
}

Zhichao Chen ${ }^{1,2}$, Xianglin Zhang ${ }^{1 *}$, Yang Yang ${ }^{3}$, Kui Zhou ${ }^{1}$, Nicholas Wragg ${ }^{2}$, Yang Liu ${ }^{2}$, Mark Lewis ${ }^{2}$, Changqing Liu $^{2 *}$

${ }^{1}$ State Key Laboratory of Materials Processing and Die \& Mould Technology, College of Materials Science and Engineering, Huazhong University of Science and Technology, Wuhan 430074, China.

${ }^{2}$ Wolfson School of Mechanical, Electrical and Manufacturing Engineering, Loughborough University, Leicestershire LE11 3TU, UK.

${ }^{3}$ State Key Laboratory Breeding Base of Basic Science of Stomatology and Key Laboratory of Oral Biomedicine Ministry of Education, School and Hospital of Stomatology, Wuhan University, Wuhan 430079, China.

hust_zxl@mail.hust.edu.cn

C.Liu@lboro.ac.uk

*Corresponding author:

\begin{abstract}
To improve the biological performance of hydroxyapatite scaffolds in bone tissue engineering, graphite was used as porogen to create additional micro/nanoporosity to macroporosity, resulting in hierarchical porosity. For maximum imitation of natural bone structures, scaffolds with different porosity features were fabricated using micron/nano-sized graphite. The sintering profile of graphite treated scaffolds was optimised to reduce the influence of shrinkage. To confirm the porosity features, the micro/nanostructures of scaffolds were characterised by scanning electron microscopy and Brunauer-Emmett-Teller method. Considering that hydroxyapatite is resistant to biodegradation in vivo, the degradation rate of scaffolds in modified simulated body fluid was examined. Furthermore, biological evaluations based on myoblasts were carried out to investigate the influence of porosity features on the essential performance such as adhesion, proliferation and differentiation. The results indicate that the scaffolds with dominant microporosity and little nanoporosity formed inside had high potential for clinical applications due to improved performance in bioactivity.
\end{abstract}

Keywords: hydroxyapatite scaffold; hierarchical porosity; porosity feature; biological performance; bone tissue engineering. 


\section{Introduction}

Apart from high porosity, complex and three-dimensional structures [1], biological performance in terms of biodegradable ability and bioactivity is also essential for scaffolds to achieve satisfactory regeneration in bone tissue engineering [2]. Owing to its similarity to the natural bones in chemical composition, $\mathrm{HA}$ (hydroxyapatite, $\mathrm{Ca}_{10}\left[\mathrm{PO}_{4}\right]_{6}[\mathrm{OH}]_{2}$ ) has become an excellent biomaterial as substitutes of natural bones [3-6]. However, the uses of HA for bone regenesis have encountered a number of technical challenges, including its resistance to biodegradation in vivo [5], low fracture toughness, and high crystallinity [3]. Therefore, attempts have been made, e.g. introducing conditioners, to modify its performance, thus to overcome certain limitation and satisfy clinical needs $[4,7,8]$. So far, the major improvements to HA are concentrated on the material composition, with a few considered from the angle of modifying structures to achieve high bio-imitability to natural bones. This work is primarily concerned with the potential approaches to fabrication of 3D complex structures with hierarchical porosity in HA scaffolds, consisting of nanoporosity, microporosity and macroporosity [9], which is expected to further enhance the biological performance.

The importance of porosity and pore structures on osteogenesis had been extensively investigated [10-12]. In general, the nanoporosity in scaffolds could significantly promote osteoinductivity during bone tissue engineering by enhancing osteogenic differentiation [13, 14], as many natural tissues like bone can be regarded as materials with some nanostructures. It was also found that both macro and micro porosity could influence osteoinductive activity to certain extent [10,11]. Particularly, the microporosity in the scaffolds is able to make substantial contribution to bone regeneration $[15,16]$. Adequate microporosity in scaffolds is also necessary to allow in-growth of capillaries to promote osteogenesis [15]. As for macroporosity, it forms 3D complex structures, which encourages migration and proliferation of osteogenic cells, as well as reinforces mechanical connection with adjacent tissues [4, 12, 17]. Nevertheless, it has presented limitations in existing traditional technologies due to uncontrollable distribution and sizes of pores in scaffolds [18-20], and recently developed 3D printing techniques are not capable of producing microporosity in nano scale [21-23]. Hence it is almost impossible to fabricate scaffolds with refined structures consisting of porosity across macro, micron and nano scale (nm - $\mu \mathrm{m}-\mathrm{mm})$ through these methods.

In this study, a new fabrication method combining the extrusion deposition [20] with porogen foaming technique was developed to construct highly porous HA scaffolds with evident hierarchical porosity [24]. The process is controllable and reproducible; it is able to create a wide range and scale of porosities with adjustable distribution in HA scaffolds, meanwhile with suitable mechanical strength. However, the scaffolds may exhibit significant difference in features and characteristics of hierarchical porosity, e.g. the ratios between microporosity and nanoporosity, which mainly depends on the particle size distribution of porogen. Therefore, it is important to evaluate the influence of 


\section{ACCEPTED MANUSCRIPT}

such difference on biological performance of scaffolds in order to optimise the structures through the control of particle sizes and distribution of porogen. In this paper, we present the process of graphite as pore former to generate in-rod porosity (additional porosity inside the rods of scaffolds), which can permit the adjustment of microporosity and nanoporosity with nano graphite (nG) or micron graphite $(\mu \mathrm{G})$. It was highly anticipated that further optimisation is possible to control the distribution of porosity in scaffolds, so that acceptable and optimal solution for bone tissue engineering may be achieved to meet the needs of clinical applications.

\section{Material and methods}

\subsection{Fabrication of scaffolds}

Scaffolds were fabricated by MAM system [20] (motor assisted micro-syringe system; MAM-II, Fochif, China) with commercially available nano HA (MH-HAp, Emperor Nano Material, China) and graphite powder in micron (300 mesh, Sinopharm Chemical Reagent, China) / nano ( 400nm; XF011, XF-Nano, China) size if necessary. Scaffolds were then sintered in furnace (KSL-1700, Kejing Materials Technology, China) at high temperature $\left(1200^{\circ} \mathrm{C}\right)[8,25]$. Other reagents used to get well dispersed slurry with favourable properties for deposition include glycerol (Sinopharm), ammonia water (Sinopharm), nitric acid (Sinopharm) and $\mathrm{NH}_{4} \mathrm{PAA}$ (ammonium polyacrylate; Goodben, China), and dispersant for graphite (HT100, Goodben) [20].

On the basis of previous work [24], three kinds of scaffolds, i.e. normal HA for control (marked as HA-n-c), HA with 25vol.\% micron graphite as pore former (short for HA- $\mu \mathrm{G}-25 \%$ ) and HA with $25 \mathrm{vol} . \%$ nano graphite (HA-nG-25\%), were prepared for characterization and evaluation in terms of microstructures and biological performance. In addition, to reduce the influence of shrinkage on in-rod porosity, TGA/DSC (thermo-gravimetric analysis / differential scanning calorimetry; TGA7, Perkin Elmer, China) was employed to record the sintering behaviour of normal and graphite treated scaffolds (HA-G).

\subsection{Characterization of morphologies}

The particle size of graphite ( $\mathrm{nG}$ and $\mu \mathrm{G}$ ) was measured by dynamic light scattering (DLS) nano-particle size analyser (LB550, Horiba Scientific, Japan). Due to poor liquidity, graphite samples were dispersed in a solution with ultrasonic vibration. The distribution and size of porosity was measured by BET method (Brunauer-Emmett-Teller; ASAP2020, Micromeritics Instrument, USA). And SEM (scanning electron microscopy; Nova NanoSEM 450, FEI, Netherlands) was used to observe the morphologies of HA scaffolds before and 1 day after cell culture. Prior to SEM, the scaffolds after cell culture were washed with phosphate buffered saline (Sinopharm) and later critical-point dried [26]. 


\subsection{Assessment of biodegradation}

Modified SBF (simulated body fluid) was prepared according to reference [27]. The materials for SBF were listed as follows: sodium chloride (AR, 99.5\%; Aladdin Bio-Chem, China), sodium bicarbonate (AR, $\geq 99.8 \%$; Aladdin), potassium chloride (AR, 99.5\%; Aladdin), potassium dihydrogen phosphate (AR, 99\%; Aladdin), magnesium chloride hexahydrate (AR, 98.0\%; Aladdin), calcium chloride (AR, 96.0\%; Aladdin), sodium sulphate (AR, 99\%; Aladdin), tris(hydroxymethyl)aminomethane ( $\geq 99.9 \%$; Aladdin), hydrochloric acid (1mol/L; Sinopharm) and standard pH solution (Sinopharm). Since HA degrades very slowly in neutral environment [5], the SBF used in this study was acidic $(\mathrm{pH}=3)$ to accelerate the degradation process. To make sure that the result could offer possible reference to in-vivo environment, the assessment was performed on the condition of water bath at $37^{\circ} \mathrm{C}$ (SHA-C, Hongke Instrument, China). The actual $\mathrm{pH}$ and weight loss was measured twice a week during the degradation test. Moreover, once the $\mathrm{pH}$ of SBF under test was larger than 5, the SBF would be renewed to maintain the actual degradation rate. The number of scaffolds (HA-n-c, HA- $\mu \mathrm{G}-25 \%$ and HA-nG-25\%) for test was 6 each.

\subsection{Evaluation of bioactivity}

To evaluate the effect of scaffolds on proliferation and cell morphology, C2C12s (myoblasts, a cell line with a visually determinable differentiation profile) [28] were incubated in growth media consisting of HG-DMEM (high-glucose Dulbecco's modified eagle medium; HyClone, GE Healthcare Life Sciences) supplemented with 20\% FBS (fetal bovine serum; FBS Biotech, PAN Biotech) and $1 \% \mathrm{P} / \mathrm{S}$ (penicillin/streptomycin, 10,000U/mL and 10,000 $\mathrm{gg} / \mathrm{mL}$; Gibco, Thermo Fisher Scientific). C2C12s were exposed to scaffolds until they were confluent (4 days). To test the influence on differentiation capacity, $\mathrm{C} 2 \mathrm{C} 12 \mathrm{~s}$ were grown until confluent in normal growth media (4 days) and then incubated with differentiation media, i.e. HG-DMEM, 2\% donor equine serum (HyClone) and $1 \mu \mathrm{M}$ insulin (Sigma-Aldrich), for three days.

At the end of experiments, cells were lysed or fixed for further analysis in $\mathrm{dH}_{2} \mathrm{O}$ or methanol and acetone (50\% v/v; Sigma-Aldrich) respectively. C2C12s used in this study were in passage 3 - 6 and seeded at 4500 cells $/ \mathrm{cm}^{2}$ onto tissue culture plastic (DNA/protein analysis) or gelatine-coated $(0.2 \%)$ coverslips (for imaging) set within a 6-well plate. The samples with $\mathrm{C} 2 \mathrm{C} 12 \mathrm{~s}$ were all incubated in a humidified $\mathrm{CO}_{2}$ incubator (Heracell 150i, Thermo Fisher Scientific) at $37^{\circ} \mathrm{C}$ during the whole process. The immucytochemical images were photographed by a fluorescence microscope (D71, Olympus, Japan).

\section{Results and discussion}

\subsection{Particle size of porogen}




\section{ACCEPTED MANUSCRIPT}

Hierarchical porosity in this paper refers to macroporosity with considerable amount of microporosity and nanoporosity inside the rods of scaffolds. The classification of above mentioned porosity was based on literatures and dimensions: macroporosity $(\geq 100 \mu \mathrm{m}$, the least required size for cell survivability [29, 30]), microporosity $(1 \sim 100 \mu \mathrm{m}$, allowing in-growth of human micro-vessels or capillaries [31]) and nanoporosity $(<1 \mu \mathrm{m}$, significantly promoting osteoinductivity through enhancing osteogenic differentiation $[13,14])$.

Based on our experience, the size and shape of chemically formed micropores or nanopores would be closely related to the original porogen; that is, after sintering, the in-rod micro- / nano-structures of scaffolds are mainly determined by the particle size and distribution of porogen. Therefore, it is of great significance to analyse the particle size and distribution of nano and micron graphite so as to predict the formation of hierarchical porosity. According to the DLS result shown in Fig.1, the particle size of $\mathrm{nG}$ was mainly focused on the range of 241 and $872 \mathrm{~nm}$ (up to $98.6 \%$ ). The extremum (where the probability of size is the highest) and average size of $\mathrm{nG}$ was 460 and 477nm respectively, meaning that it is reasonable to use such $\mathrm{nG}$ to create in-rod nanoporosity. On the other hand, the distribution of $\mu \mathrm{G}$ was relatively dispersive, possibly due to the fragility and aggregation of $\mu \mathrm{G}$ sample. But the $\mu \mathrm{G}$ particles between 10 and $100 \mu \mathrm{m}$ was still in the majority (over $70 \%$ ), indicating the ability to form considerable in-rod microporosity. Although the extremum $(27.4 \mu \mathrm{m})$ was not close to the average size $(53.4 \mu \mathrm{m})$, the size distribution of $\mu \mathrm{G}$ was uniform. Overall, owing to uniform distribution of particle size, both $\mathrm{nG}$ and $\mu \mathrm{G}$ were suitable as porogen to create additional in-rod porosity, which results in hierarchically porous structures.

\subsection{Optimization of sintering process}

It is highly desired that the nanoporosity or microporosity formed by chemical reagents and porogen could be preserved as much as possible after sintering at high temperature. In this study, TGA/DSC was employed to analyse the sintering behaviour of normal scaffold (0vol.\% graphite) and HA-G scaffold (25vol.\% graphite). And the result was taken as a reference for the optimisation of sintering process which was expected to reduce the influence of shrinkage on in-rod porosity. It was found that two critical stages regarding weight loss and energy emission, at $220^{\circ} \mathrm{C}$ and $850^{\circ} \mathrm{C}$ respectively, occurred during the TGA/DSC analysis of HA-G (Fig.2(a)). As for normal scaffolds, there was only one critical stage at $220^{\circ} \mathrm{C}$. By comparision, it can be concluded that the stage at $220^{\circ} \mathrm{C}$ in both scaffolds was mainly the result of the oxidation of chemical reagents, used for well dispersed slurry as mentioned. This stage contributed to forming nanoporosity as well, which is favourable to osteoinductivity. Another one in HA-G samples should be the combustion of graphite, which starts from $600^{\circ} \mathrm{C}$ and ends at $1000^{\circ} \mathrm{C}$, since the temperature was consistent to the ignition temperature of graphite. In practical, to maximise the final quantity of in-rod microporosity or nanoporosity, the optimisation of sintering process for HA-G scaffolds was commenced according to the two critical stages, shown in Fig.2(b). Note that the sintering profile was developed on the basis of general sintering process $[25,32]$. To be more specific, the initial holding temperature was $250^{\circ} \mathrm{C}$ so that the 


\section{ACCEPTED MANUSCRIPT}

most of nanoporosity could be preserved after the removal of chemical reagents. In addition, another holding condition $\left(900^{\circ} \mathrm{C}\right.$ for $\left.2 \mathrm{~h}\right)$ was supplemented specially for complete combustion of graphite, so as to reduce the shrinking rate of additional in-rod porosity. In this way, it was anticipated that the remained amount of micro- or nano-porosity could be substantially increased. And that the actual set of holding temperatures was a bit higher than critical values was to ensure complete burning of reagents or graphite. Most of all, such optimisation turned out to work, which would be described in following sections. Another worth mentioning point is HA-G scaffolds were sintered with optimised profile, but normal scaffolds (with average amount of graphite dispersant as control) were still under general process to identify the potential advantages of optimised sintering process.

\subsection{Morphologies of scaffolds}

The microstructures of scaffolds were characterized by SEM. The SEM images (Fig.3) show that the surface of normal scaffold was much smooth in spite of little roughness; on the contrary, HA-G scaffolds contained massive micro and nanopores inside the filament rods, which resulted in high wall roughness and made the porosity hierarchical. Furthermore, great difference was found between HA-nG-25\% and HA- $\mu \mathrm{G}-25 \%$ in terms of surface morphologies. Specifically, the micropores ranging from 30 to $100 \mu \mathrm{m}$ in size were more evident in $\mathrm{HA}-\mu \mathrm{G}-25 \%$ sample, due to the utilisation of $\mu \mathrm{G}$ as pore former. In addition, the distribution of microporosity in HA-nG-25\% was more uniform than $\mu \mathrm{G}$ treated scaffolds. A possible explanation is that micron graphite was more likely to be broken up during ultrasonic dispersion, because graphite is laminar and fragile in general.

In view of that nanostructures have significant influence over the biological performance of scaffolds, BET, which measures the specific surface area (SSA) according to physical adsorption of a gas on the surface, was employed to study the nano properties of normal and HA-G scaffolds. Fig.4 presents the distribution of pores between 1 to $400 \mathrm{~nm}$ in all scaffolds according to BET. For the nanopores smaller than $50 \mathrm{~nm}$, graphite treated scaffolds were advantageous to normal scaffolds in terms of SSA, owing to the optimised sintering process. So it was confirmed that such optimisation indeed contributed to preserving nanoporosity. Besides, considerable difference was also found in nanopores with larger size (100 - 400nm); that is, HA-nG-25\% scaffolds shew absolute superiority in pore area over HA-n-c and HA- $\mu \mathrm{G}-25 \%$, on account of the particle size of $n G$. Interestingly, in the range of $1-100 \mathrm{~nm}$, the SSA of $\mathrm{HA}-\mu \mathrm{G}-25 \%$ was a bit higher than HA-nG-25\%, although of the same order of magnitude. It is because more dispersant was added to get micron graphite well dispersed in HA slurry, while nano graphite needed less due to good dispersion.

Now that the purpose of porogen was to produce additional in-rod porosity, the actual ratio of porosity and average pore size in each scale ( $\mathrm{nm}, \mu \mathrm{m}$ and $\mathrm{mm}$ ) was listed in Table I to verify the formation of hierarchically porous structures. The data was beneficial to understand the overall distribution of porosity. And the source of data, either calculated or estimated, was demonstrated with footnote. From Table I we can see that the porosity of HA-n-c was almost completely (about 


\section{ACCEPTED MANUSCRIPT}

$98 \%$ ) occupied with macropores ( $\geq 100 \mu \mathrm{m}$ ), and the distribution of microporosity in HA-G scaffolds was consistent to the original of graphite. In addition, the amount of nanoporosity in $\mathrm{HA}-\mu \mathrm{G}-25 \%$ was higher than normal scaffold, which also confirms the positive contribution made by the optimisation of sintering. Most of all, the average pore size in each range indicates that the structures were hierarchically porous. Thus it can be seen from Fig. 3 and Table I that the addition of graphite as pore former really succeeded in creating hierarchical porosity. However, the microporosity in HA-nG-25\% was possibly inadequate to allow full in-growth of cells [33], although further research is required to affirm this. So compared to HA-nG-25\%, it is likely that the distribution of porosity and pore size in $\mathrm{HA}-\mu \mathrm{G}-25 \%$ was more favourable, owing to large number of micropores.

Table I Estimated porosity (\%) and average pore size $(\mu \mathrm{m})$

\begin{tabular}{|c|c|c|c|c|c|c|c|c|}
\hline Porosity & $\leq 0.4^{a}$ & $\geq 100^{b}$ & $0.4-100^{c}$ & Total $^{d}$ & Average Size & $\leq 0.4^{a}$ & $\geq 100^{e}$ & $0.4-100^{e}$ \\
\hline$H A-n-c$ & 0.4 & $\sim 55.8$ & 0.6 & 56.8 & $H A-n-c$ & 0.008 & $\sim 347$ & $\sim 5$ \\
\hline$H A-n G-25 \%$ & 11.7 & $\sim 55.8$ & 1.3 & 68.8 & $H A-n G-25 \%$ & 0.132 & $\sim 326$ & $\sim 15$ \\
\hline$H A-\mu G-25 \%$ & 0.9 & $\sim 55.8$ & 12.7 & 69.4 & $H A-\mu G-25 \%$ & 0.010 & $\sim 332$ & $\sim 37$ \\
\hline
\end{tabular}

${ }^{\mathrm{a}}$ From BET.

${ }^{\mathrm{b}}$ Calculated by theoretical model, assuming that scaffolds could manage to keep original shapes after sintering.

${ }^{\mathrm{c}}$ By calculation of $\boldsymbol{P}_{\text {Total }}-\boldsymbol{P}_{\mathbf{0 . 4}}-\boldsymbol{P}_{\mathbf{1 0 0}}$.

${ }^{\mathrm{d}}$ Calculated by gravimetry method.

${ }^{\mathrm{e}}$ Measured according to SEM images.

\subsection{Analysis of degradation}

It is known that HA is hardly biodegradable in vivo $(\mathrm{pH}=\sim 7.4)$ in short term. Thus in order to show the influence of hierarchical porosity on degradation and make the degradation rate acceptable, acidic SBF $(\mathrm{pH}=3)$ based on modified SBF [34] was prepared to accelerate the process, merely for the purpose of comparison (not for evaluation). Eq.(I) [35] illustrates the decomposition of HA in acidic environment. Weight loss and $\mathrm{pH}$ value (Fig.5) was monitored twice a week to record the process of degradation, though decomposition actually. However, due to high porosity and brittleness, HA scaffolds were easy to be broken up into tiny fragments especially after certain time of degradation (Fig.6), affecting the accuracy of weight measurement more or less $(<1.2 \%)$.

$$
\mathrm{Ca}_{10}\left[\mathrm{PO}_{4}\right]_{6}[\mathrm{OH}]_{2}+8 \mathrm{H}^{+} \rightarrow 10 \mathrm{Ca}^{2+}+6 \mathrm{HPO}_{4}^{2-}+2 \mathrm{H}_{2} \mathrm{O}
$$

Fig. 5 shows that only $51 \%$ was decomposed after 7 weeks in normal scaffolds, but the rate in HA-G scaffolds was higher (75\% off HA-nG-25\% and $67 \%$ off HA- $\mu \mathrm{G}-25 \%)$, due to extremely large SSA and high porosity which promotes the ability of biodegradation. Nonetheless, the degradation of all scaffolds exhibited similar trend, i.e. slow decomposition at initial stage and followed by 


\section{ACCEPTED MANUSCRIPT}

increasing rate. It was found that $\mathrm{HA}-\mathrm{nG}-25 \%$ scaffolds required the most frequent renewal of SBF solution while normal group needed the least. From the point of view of chemical reaction in Eq.(I), the $\mathrm{pH}$ value would be accordingly elevated as $\mathrm{H}^{+}$was continuously consumed. Additionally, once the solution was refreshed, the decomposition process would be consequently accelerated in the following several days. To our best knowledge, the renewal of SBF surely increased the concentration of $\mathrm{H}^{+}$, and thus boosted the reaction rate, according to chemical equilibrium. Overall, the decomposition rate of HA scaffolds was significantly improved ( $\geq 31 \%$ ) in HA-G scaffolds due to additional micro and nano porosity. It is highly likely that the actual biodegradation rate of HA-G scaffolds in vivo could also be accelerated at similar level, and best performance was found in HA-nG-25\%.

To make the process of decomposition intuitive, the appearance of scaffolds decomposed after day 24 and 49 days was shown in Fig.6. Despite carefulness during operation, the breakup of HA scaffolds into fragments was still inevitable. Even worse, the more being degraded, the scaffolds would be more loose and brittle (Fig.6 (c) and (f)), which also was to blame for the growing deviation of weight loss as time went by (Fig.5). Besides, the scaffolds preferred to begin degradation on the edge and corner parts that possess larger SSA.

\subsection{Evaluation of bioactivity}

To evaluate the effect of microporosity features on proliferation and differentiation, the concentration of DNA (indicator of cell numbers) and protein/DNA ratio, which reflects cell size, was measured. According to Fig.7(a), the proliferation was promoted substantially in HA-G scaffolds, and the performance in $\mathrm{HA}-\mu \mathrm{G}-25 \%$ group was improved the most (day 4). Interestingly, the number of cells during differentiation period in normal scaffolds was higher than the HA-G scaffolds (day 7, Fig.7(a)); while only slight difference was observed in protein/DNA ratio after total culture in all scaffolds (day 7, Fig.7(b)). It was also found that the difference of cell number (DNA) shew opposite trend to cell size (protein/DNA), both at day 4 and 7. This phenomenon can be explained from the angle of space occupancy: given that the scaffolds were fully occupied with live cells, the number of cells with smaller sizes would be reasonably higher than larger ones. Furthermore, the results also mean that HA-G scaffolds would not cause toxic effects on cells during cell culture, providing another evidence for successful removal of graphite after sintering. However, it needs further experiments to conclude the influence of porosity features on bioactivity.

In order to know what made the difference in proliferation, SEM was employed to observe the initial adhesion status of myoblasts on scaffolds (1 day after cell culture). In Fig.8 (a), (c) and (e), the features of surface morphologies and roughness on all scaffolds were evident, also indicating hierarchically porous structures in HA-G scaffolds. The images show that the cells in HA-G scaffolds tended to adhere and spread much more freely on the surfaces, in contrast to the restricted and cramped adhesion on normal scaffolds. In addition, the tentacles of cells in HA-n-c could hardly 


\section{ACCEPTED MANUSCRIPT}

be recognized due to poor adhesion. Whereas in $\mathrm{HA}-\mathrm{nG}-25 \%$ and $\mathrm{HA}-\mu \mathrm{G}-25 \%$ sample, the tentacles were more likely to join together as expected, which could build favourable foundation for cell interactions [36]. Another significant difference lies in the aspect of cell aggregation, wherein HA-G scaffolds exhibit complete superiority to normal ones, which could greatly enhance the efficiency of transferring biological signals [37]. Consequently, in view of adhesion, interaction and signalling, HA-G scaffolds were able to promote the proliferation notably during cell culture, in agreement with the difference of DNA concentration (day 4) in Fig.7.

The ability that promotes the formation of skeletal muscle during bone tissue engineering was evaluated to analyse the differentiation process of myoblasts through fluorescence, as shown in Fig.9, which illustrates the differentiation of $\mathrm{C} 2 \mathrm{C} 12 \mathrm{~s}$ into multinucleated myotubes at day 7 . The number of cells (DNA in blue) in all scaffolds was almost the same, fully in agreement with the DNA concentration (day 7) in Fig.7. Obviously, the formation of myotubes was definite in all scaffolds, owing to good biocompatibility of HA. However, the myotubes in HA-nG-25\% and HA-n-c scaffold were still under the formative period, yet the formation stage in normal scaffold was even earlier than HA-nG-25\%; while the formation of myotubes was much more mature to be identified. It means that $\mu \mathrm{G}$ treated scaffolds exerted better performance in promoting the differentiation of myoblasts into myotubes, compared to scaffolds treated with nG. A possible explanation is, apart from more evident hierarchical porosity, the distribution of porosity in $\mathrm{HA}-\mu \mathrm{G}-25 \%$ scaffolds was closer to natural bone tissues. In addition, the micropores $(30 \sim 50 \mu \mathrm{m})$ could allow extra space for in-growth of cells, which are usually about $20 \mu \mathrm{m}$ in diameter [38]. The BET results also reveal that there was considerable amount of nanoporosity in $\mathrm{HA}-\mu \mathrm{G}-25 \%$ scaffolds, which could contribute to osteoinductivity and bioactivity as well.

The results in Fig.7 can be explained by further investigation into Fig.8 and 9. Due to lack of cell interactions, the myoblasts tends to grow up instead of increasing cell divisions to make preparation for differentiation [39]. So the cell number of normal scaffolds was the least and the cell size was the largest. On the contrary, the scaffolds treated with $\mu \mathrm{G}$ had more advantages in interactions, transfer of signals and more space for proliferation. Moreover, the micropores in HA- $\mu \mathrm{G}-25 \%$ scaffolds may form valid channels for the conduction of nutrition and store certain amount of nutrition inside the rods [40, 41], which improved the survival rate of cells. On the other hand, the decrease of cell size from growth media to differentiation media was getting smaller (normal $>n G>\mu G$ ), and the cell size of HA- $\mu \mathrm{G}-25 \%$ group was almost the same. In other words, it suggests that the cells in $\mu \mathrm{G}$ treated group were the most prepared for differentiation, because the cell number and size was extremely similar during both periods. And the formation of myotubes in Fig.9 also confirms this. Therefore, although cultured in differentiation media, the myoblasts in control group had to make more preparation for differentiation, e.g. cell division, which increases the number of cells dramatically with sharp decrease in cell size. As a result, the process of myoblasts differentiating into myotubes was "delayed". As for HA-nG-25\%, since the porosity features and the performance in 


\section{ACCEPTED MANUSCRIPT}

proliferation and differentiation was between normal and $\mu \mathrm{G}$ treated scaffolds, the discussion can also apply to it. In conclusion, micron graphite was more suitable to serve as pore former in this method to fabricate bioactive scaffolds with hierarchical porosity for bone tissue engineering.

\section{Conclusions}

The hierarchically porous structures were evident in HA-G scaffolds, regardless of the different features and characteristics in porosity. Compared to normal scaffolds, the advantages of hierarchical porosity in HA-G scaffolds were substantial in terms of biological performance, including biodegradation, proliferation, adhesion, and differentiation. And the difference in the ratios of microporosity and nanoporosity would also significantly influence the performance in biodegradation and differentiation. However, such difference in porosity features had slight impacts on adhesion and proliferation. In addition, the differentiation of myoblasts into myotubes in vitro indicates that the distribution of pore size and porosity in $\mathrm{HA}-\mu \mathrm{G}-25 \%$ was relatively more advantageous than HA-nG-25\%, possibly because it was closer to the structures of natural bones. In consideration of the excellent promotion of degradation in HA-nG-25\%, a mixture of micron and nano graphite as pore former might be the optimal for highly bioactive scaffolds.

\section{Acknowledgements}

The research was funded by several programmes, i.e. National Natural Science Foundation of China (No. 81371939 \& 31270150) and State Key Lab of Materials Processing and Die \& Mould Technology (No. 2014-5). The authors would also like to acknowledge the Analytical and Testing Centre of Huazhong University of Science and Technology for SEM analysis.

\section{Reference}

[1] S.J. Hollister, Porous scaffold design for tissue engineering, Nature materials 4 (7) (2005) 518-524.

[2] L.L. Hench, J.M. Polak, Third-generation biomedical materials, Science 295 (5557) (2002) 1014-1017.

[3] Z. Dong, Y. Li, Q. Zou, Degradation and biocompatibility of porous nano-hydroxyapatite/polyurethane composite scaffold for bone tissue engineering, Applied Surface Science 255 (12) (2009) 6087-6091.

[4] G. Wei, P.X. Ma, Structure and properties of nano-hydroxyapatite/polymer composite scaffolds for bone tissue engineering, Biomaterials 25 (19) (2004) 4749-4757.

[5] K. Yamaguchi, T. Hirano, G. Yoshida, K. Iwasaki, Degradation-resistant character of synthetic hydroxyapatite 


\section{ACCEPTED MANUSCRIPT}

blocks filled in bone defects, Biomaterials 16 (13) (1995) 983-985.

[6] D. Xiao, X. Zhou, H. Li, Y. Fu, K. Duan, X. Lu, X. Zheng, J. Weng, Fabrication of hollow hydroxyapatite particles assisted by small organic molecule and effect of microstructure on protein adsorption, Journal of the European Ceramic Society 35 (6) (2015) 1971-1978.

[7] N. Pramanik, S. Mohapatra, S. Alam, P. Pramanik, Synthesis of hydroxyapatite/poly (vinyl alcohol phosphate) nanocomposite and its characterization, Polymer Composites 29 (4) (2008) 429-436.

[8] K. Zhou, C. Dong, X. Zhang, L. Shi, Z. Chen, Y. Xu, H. Cai, Preparation and characterization of nanosilver-doped porous hydroxyapatite scaffolds, Ceramics International 41 (1) (2015) 1671-1676.

[9] J.J. Norman, T.A. Desai, Methods for fabrication of nanoscale topography for tissue engineering scaffolds, Annals of Biomedical Engineering 34 (1) (2006) 89-101.

[10] H. Yuan, Z. Yang, Y. Li, X. Zhang, J. De Bruijn, K. De Groot, Osteoinduction by calcium phosphate biomaterials, Journal of Materials Science: Materials in Medicine 9 (12) (1998) 723-726.

[11] H. Fan, T. Ikoma, J. Tanaka, X. Zhang, Surface structural biomimetics and the osteoinduction of calcium phosphate biomaterials, Journal of Nanoscience and Nanotechnology 7 (3) (2007) 808-813.

[12] V. Karageorgiou, D. Kaplan, Porosity of 3D biomaterial scaffolds and osteogenesis, Biomaterials 26 (27) (2005) 5474-5491.

[13] K.C. Popat, K.I. Chatvanichkul, G.L. Barnes, T.J. Latempa, C.A. Grimes, T.A. Desai, Osteogenic differentiation of marrow stromal cells cultured on nanoporous alumina surfaces, Journal of Biomedical Materials Research Part A 80 (4) (2007) 955-964.

[14] M. Schürmann, A. Wolff, D. Widera, S. Hauser, P. Heimann, A. Hütten, C. Kaltschmidt, B. Kaltschmidt, Interaction of adult human neural crest-derived stem cells with a nanoporous titanium surface is sufficient to induce their osteogenic differentiation, Stem Cell Research 13 (1) (2014) 98-110.

[15] K. Arvidson, B. Abdallah, L. Applegate, N. Baldini, E. Cenni, E. Gomez - Barrena, D. Granchi, M. Kassem, Y. Konttinen, K. Mustafa, Bone regeneration and stem cells, Journal of Cellular and Molecular Medicine 15 (4) (2011) 718-746.

[16] S.J. Polak, S.K.L. Levengood, M.B. Wheeler, A.J. Maki, S.G. Clark, A.J.W. Johnson, Analysis of the roles of microporosity and BMP-2 on multiple measures of bone regeneration and healing in calcium phosphate scaffolds, Acta Biomaterialia 7 (4) (2011) 1760-1771.

[17] Y. Kuboki, H. Takita, D. Kobayashi, E. Tsuruga, M. Inoue, M. Murata, N. Nagai, Y. Dohi, H. Ohgushi, BMP-induced osteogenesis on the surface of hydroxyapatite with geometrically feasible and nonfeasible structures: topology of osteogenesis, Journal of Biomedical Materials Research 39 (2) (1998) 190-199.

[18] A. Pfister, R. Landers, A. Laib, U. Hübner, R. Schmelzeisen, R. Mülhaupt, Biofunctional rapid prototyping for tissue - engineering applications: 3D bioplotting versus 3D printing, Journal of Polymer Science Part A: Polymer Chemistry 42 (3) (2004) 624-638.

[19] H. Cao, N. Kuboyama, A biodegradable porous composite scaffold of PGA/ $\beta$-TCP for bone tissue engineering, Bone 46 (2) (2010) 386-395.

[20] W. Huang, X. Zhang, Q. Wu, B. Wu, Fabrication of HA/ $\beta$-TCP scaffolds based on micro-syringe extrusion system, Rapid Prototyping Journal 19 (5) (2013) 319-326.

[21] D.W. Hutmacher, M. Sittinger, M.V. Risbud, Scaffold-based tissue engineering: rationale for computer-aided design and solid free-form fabrication systems, TRENDS in Biotechnology 22 (7) (2004) 354-362.

[22] B. Leukers, H. Gülkan, S.H. Irsen, S. Milz, C. Tille, M. Schieker, H. Seitz, Hydroxyapatite scaffolds for bone tissue engineering made by 3D printing, Journal of Materials Science: Materials in Medicine 16 (12) (2005) 1121-1124.

[23] C.X.F. Lam, X. Mo, S.-H. Teoh, D. Hutmacher, Scaffold development using 3D printing with a starch-based 


\section{ACCEPTED MANUSCRIPT}

polymer, Materials Science and Engineering: C 20 (1) (2002) 49-56.

[24] Z. Chen, X. Zhang, K. Zhou, H. Cai, C. Liu, Novel fabrication of hierarchically porous hydroxyapatite scaffolds with refined porosity and suitable strength, Advances in Applied Ceramics 114 (3) (2015) 183-187.

[25] Q. Wu, X. Zhang, B. Wu, W. Huang, Effects of microwave sintering on the properties of porous hydroxyapatite scaffolds, Ceramics International 39 (3) (2013) 2389-2395.

[26] I.K. Buckley, K.R. Porter, Electron microscopy of critical point dried whole cultured cells, Journal of microscopy 104 (2) (1975) 107-120.

[27] P. Siriphannon, Y. Kameshima, A. Yasumori, K. Okada, S. Hayashi, Formation of hydroxyapatite on CaSiO 3 powders in simulated body fluid, Journal of the European Ceramic Society 22 (4) (2002) 511-520.

[28] T. Katagiri, A. Yamaguchi, M. Komaki, E. Abe, N. Takahashi, T. Ikeda, V. Rosen, J.M. Wozney, A. Fujisawa-Sehara, T. Suda, Bone morphogenetic protein-2 converts the differentiation pathway of $\mathrm{C} 2 \mathrm{C} 12$ myoblasts into the osteoblast lineage, The Journal of cell biology 127 (6) (1994) 1755-1766.

[29] S. Hulbert, F. Young, R. Mathews, J. Klawitter, C. Talbert, F. Stelling, Potential of ceramic materials as permanently implantable skeletal prostheses, Journal of biomedical materials research 4 (3) (1970) 433-456.

[30] J. Rouwkema, N.C. Rivron, C.A. van Blitterswijk, Vascularization in tissue engineering, Trends in biotechnology 26 (8) (2008) 434-441.

[31] A. Maton, Human biology and health, Prentice Hall, 1997.

[32] G. Muralithran, S. Ramesh, The effects of sintering temperature on the properties of hydroxyapatite, Ceramics International 26 (2) (2000) 221-230.

[33] S. Bose, M. Roy, A. Bandyopadhyay, Recent advances in bone tissue engineering scaffolds, Trends in biotechnology 30 (10) (2012) 546-554.

[34] A. Oyane, H.M. Kim, T. Furuya, T. Kokubo, T. Miyazaki, T. Nakamura, Preparation and assessment of revised simulated body fluids, Journal of Biomedical Materials Research Part A 65 (2) (2003) 188-195.

[35] D. Choi, K.G. Marra, P.N. Kumta, Chemical synthesis of hydroxyapatite/poly ( $\varepsilon$-caprolactone) composites, Materials Research Bulletin 39 (3) (2004) 417-432.

[36] G. Kirmizidis, M.A. Birch, Microfabricated grooved substrates influence cell-cell communication and osteoblast differentiation in vitro, Tissue Engineering Part A 15 (6) (2008) 1427-1436.

[37] A.E. Aplin, A.K. Howe, R. Juliano, Cell adhesion molecules, signal transduction and cell growth, Current opinion in cell biology 11 (6) (1999) 737-744.

[38] M.F. Pittenger, A.M. Mackay, S.C. Beck, R.K. Jaiswal, R. Douglas, J.D. Mosca, M.A. Moorman, D.W. Simonetti, S. Craig, D.R. Marshak, Multilineage potential of adult human mesenchymal stem cells, science 284 (5411) (1999) 143-147.

[39] C. Palumbo, S. Palazzini, G. Marotti, Morphological study of intercellular junctions during osteocyte differentiation, Bone 11 (6) (1990) 401-406.

[40] M. Dinca, A. Dailly, Y. Liu, C.M. Brown, D.A. Neumann, J.R. Long, Hydrogen storage in a microporous metal-organic framework with exposed Mn2+ coordination sites, Journal of the American Chemical Society 128 (51) (2006) 16876-16883.

[41] G. He, X. Deng, Y.K. Cen, X.Y. Li, E. Luo, R.R. Nie, Y. Zhao, Z.H. Liang, Z.Q. Chen, Development and characterization of nano-TiO2/HA composite bioceramic coating on titanium surface, in: Key Engineering Materials, Vol. 336, Trans Tech Publ, 2007, pp. 1802-1805. 


\section{ACCEPTED MANUSCRIPT}

Figure 1 The distribution of particle size by DLS analyser: (a) $n G$, (b) $\mu \mathrm{G}$.

Figure 2 (a) Sintering behaviour of normal and HA-G scaffold (note that TGA stands for residual mass, and DSC records the emission of energy during analysis), (b) optimised sintering profile for HA-G scaffolds.

Figure 3 Morphologies of scaffolds after sintering at $1200^{\circ} \mathrm{C}$ : (a) HA-n-c, (b) HA-nG-25\%, (c) HA- $\mu \mathrm{G}-25 \%$. Scale $\operatorname{bar}=100 \mu \mathrm{m}$.

Figure 4 BET results of SSA and pore size distribution (1 - 400 in blue means total).

Figure 5 Degradation rate of all scaffolds in modified $\mathrm{SBF}(\mathrm{pH}=3$; Renewed when $\mathrm{pH} \geq 5$ ).

Figure 6 Scaffolds after degradation in modified SBF: $H A-n-c$ at (a) 24 days, (b) 49 days; $H A-n G-25 \%$ at (c) 24 days, (d) 49 days; $H A-\mu G-25 \%$ at (e) 24 days, (f) 49 days. Scale bar $=5 \mathrm{~mm}$.

Figure 7 C2C12s incubated in growth media for 4 days followed by differentiation media for another 3 days: (a) DNA ( $\mathrm{p} \leq 0.05)$, (b) Protein/DNA $(\mathrm{p} \leq 0.01) . \mathrm{n}=3$.

Figure 8 SEM images for adhesion status of C2C12s on scaffolds (day 1): (a), (b) HA-n-c; (c), (d) HA-nG-25\%; (e), (f) HA- $\mu \mathrm{G}-25 \%$. Scale bar $=20 \mu \mathrm{m}$.

Figure 9 Immucytochemical images displaying multinucleated myotubes (day 7): (a) HA-n-c, (b) HA-nG-25\%, (c) HA- $\mu \mathrm{G}-25 \%$. Red (phalloidin-TRITC) - F-actin, Blue (DAPI) - DNA. Scale bar $=40 \mu \mathrm{m}$.

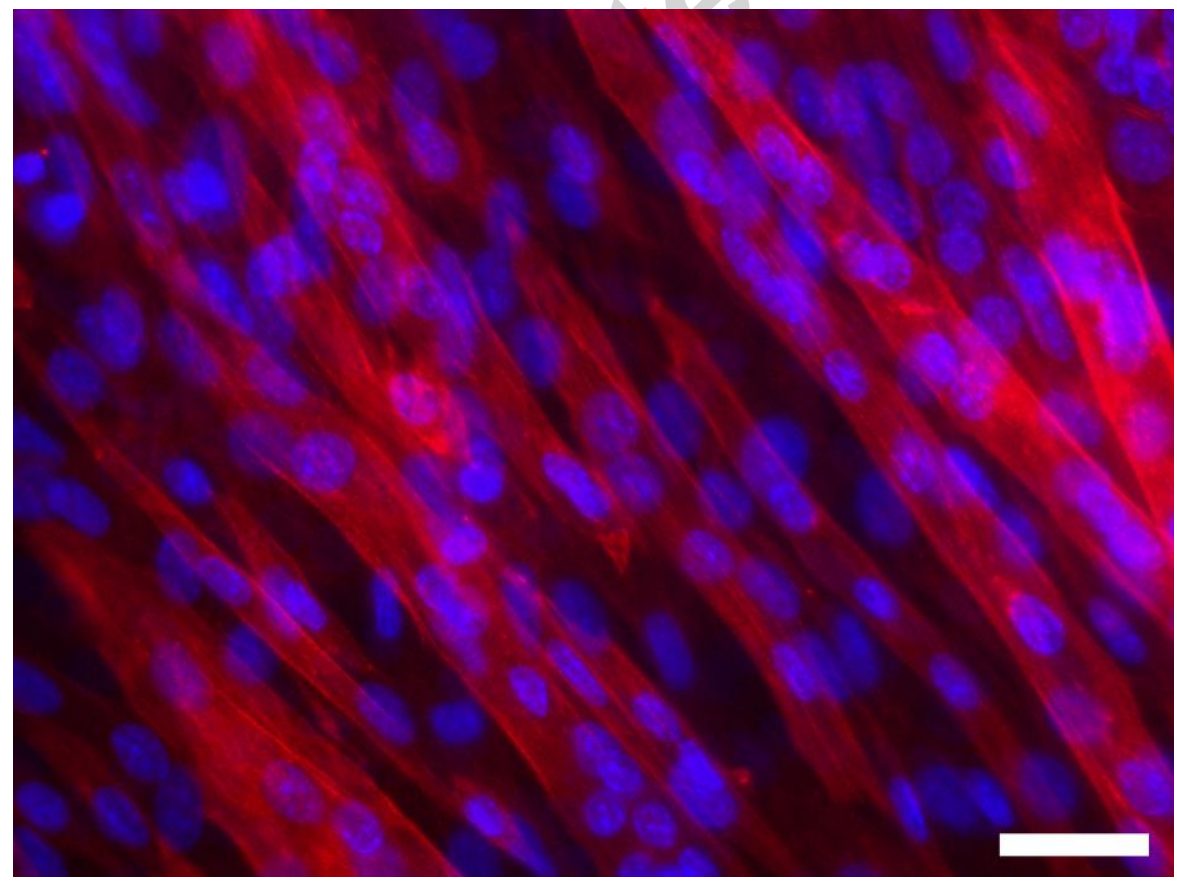




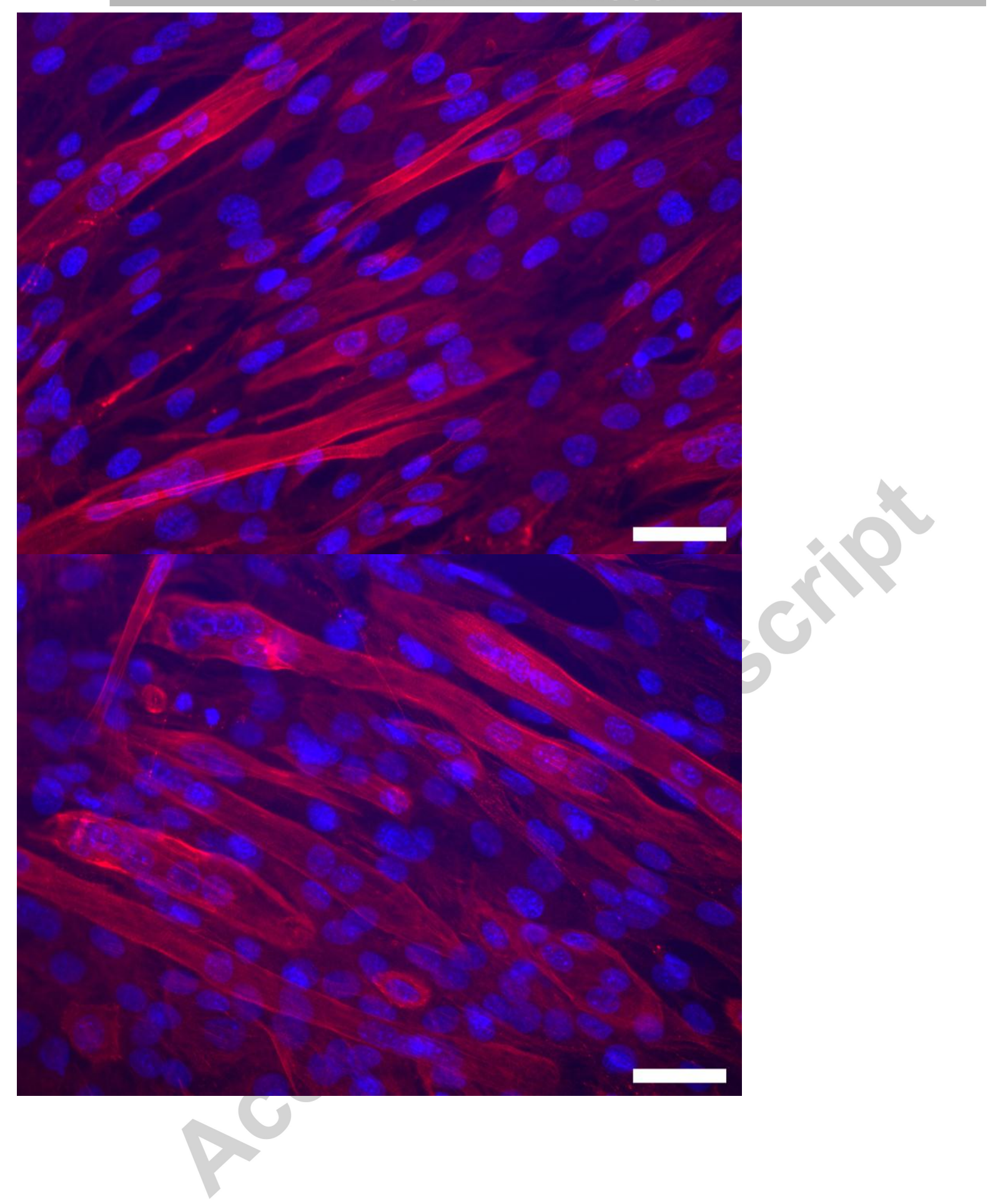




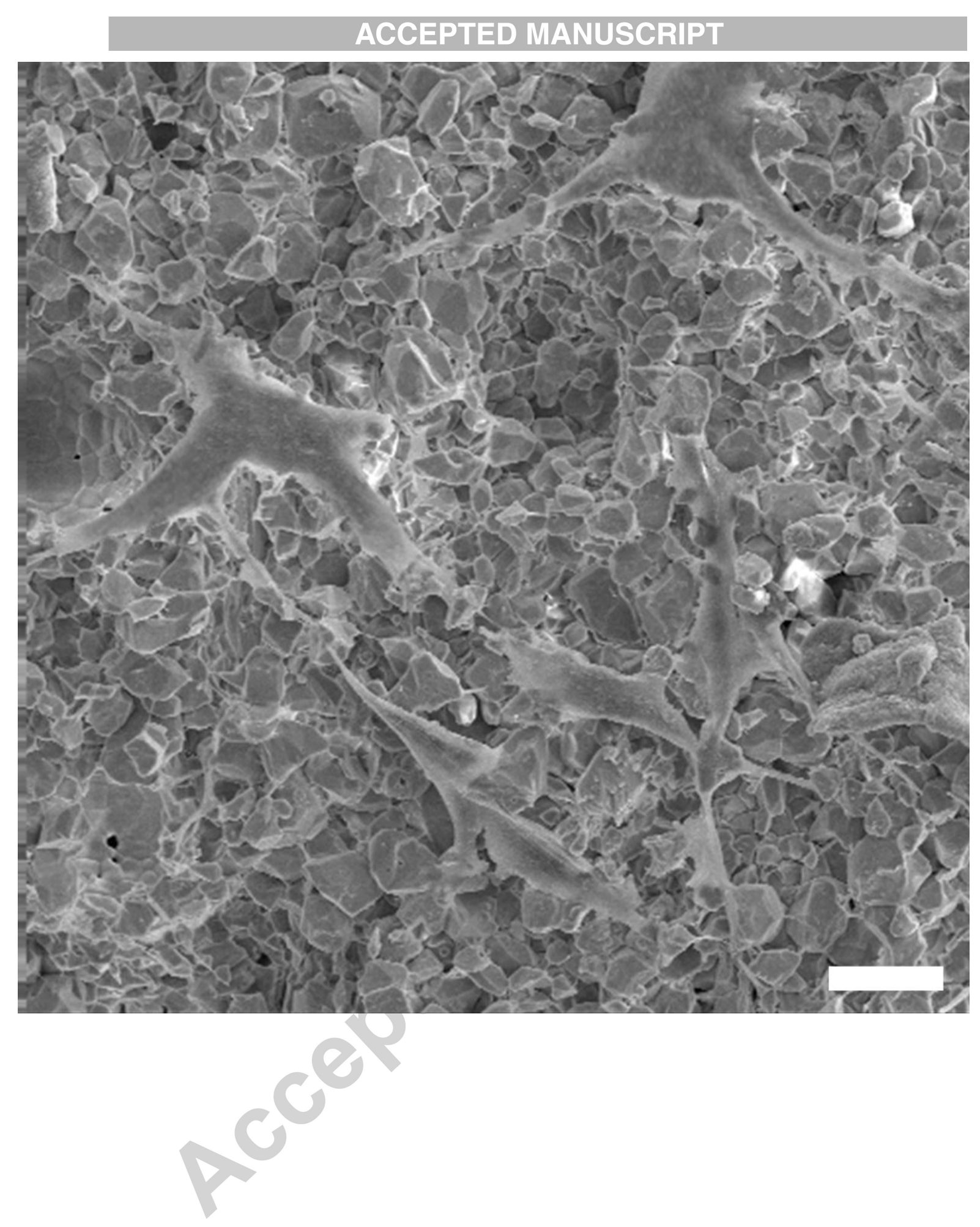




\section{ACCEPTED MANUSCRIPT}

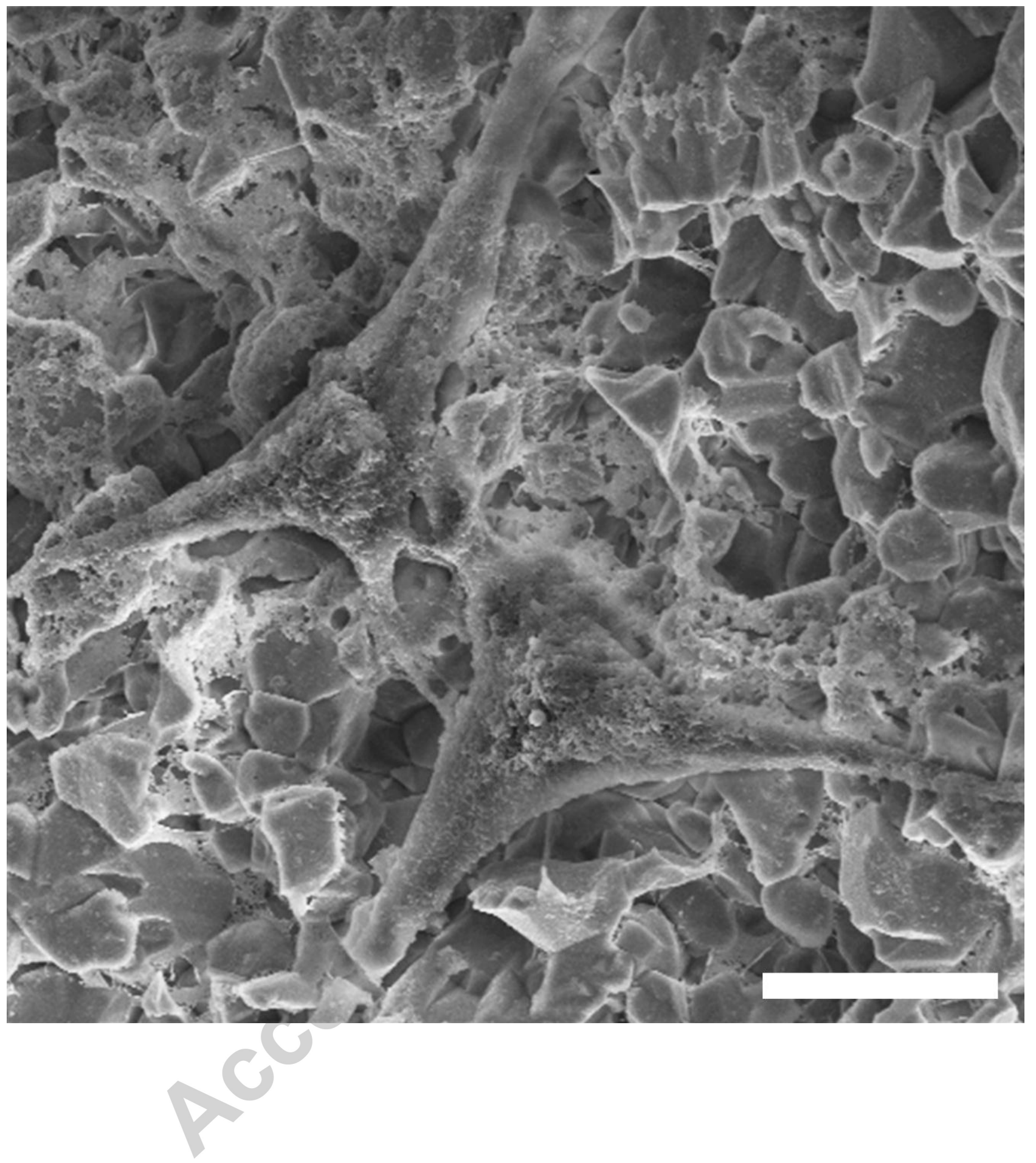




\section{ACCEPTED MANUSCRIPT}
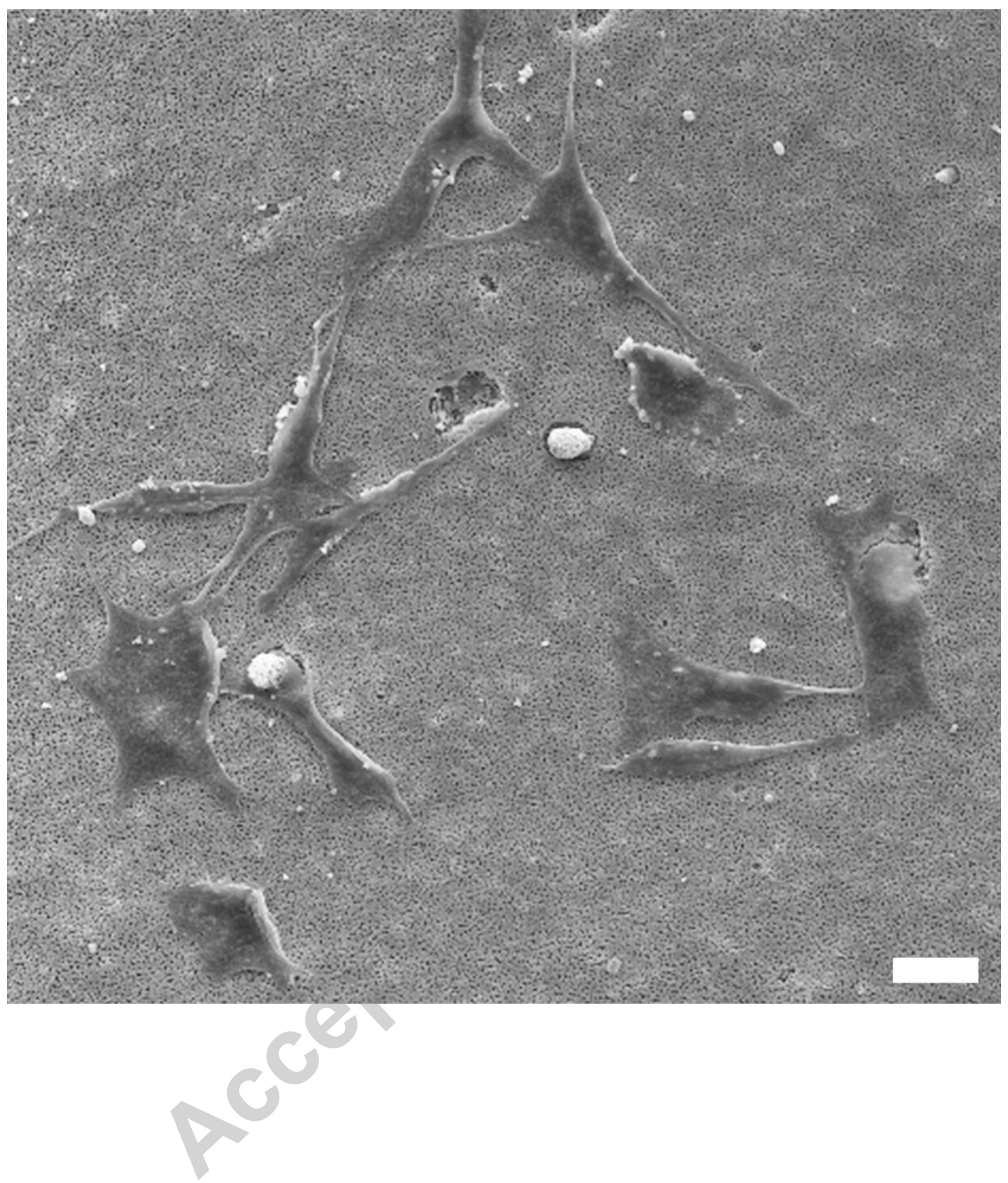
ACCEPTED MANUSCRIPT

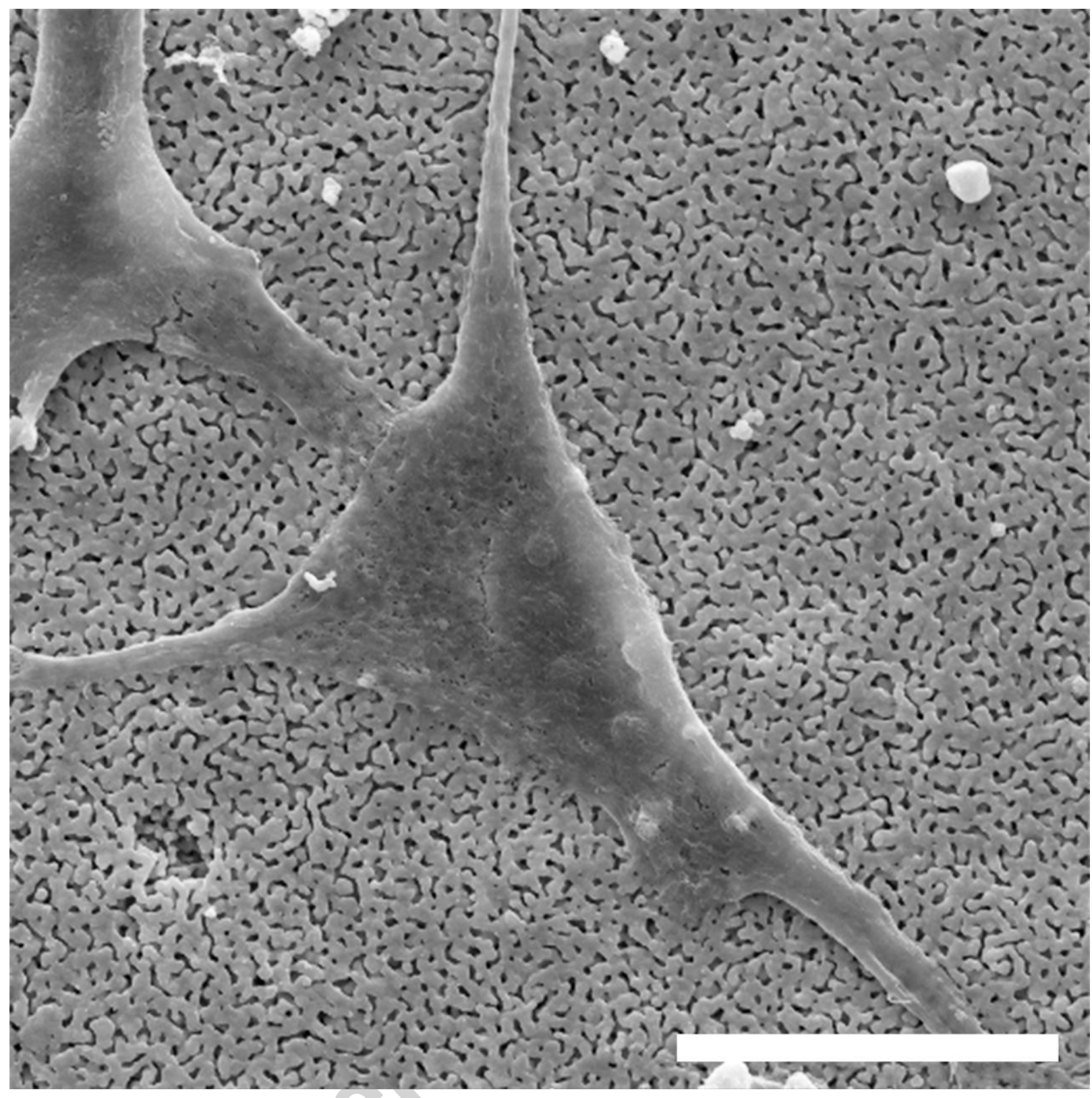




\section{ACCEPTED MANUSCRIPT}

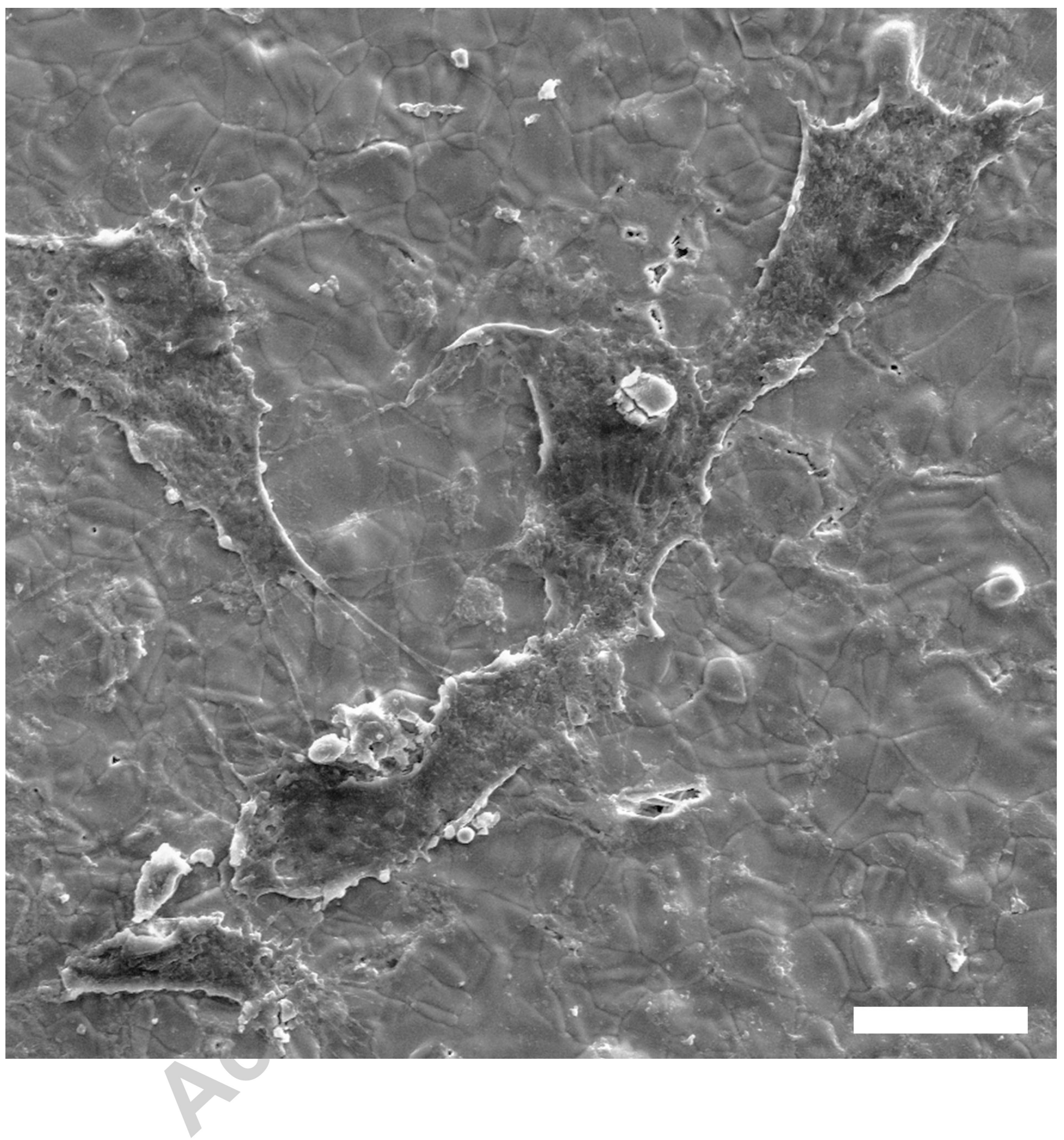




\section{ACCEPTED MANUSCRIPT}
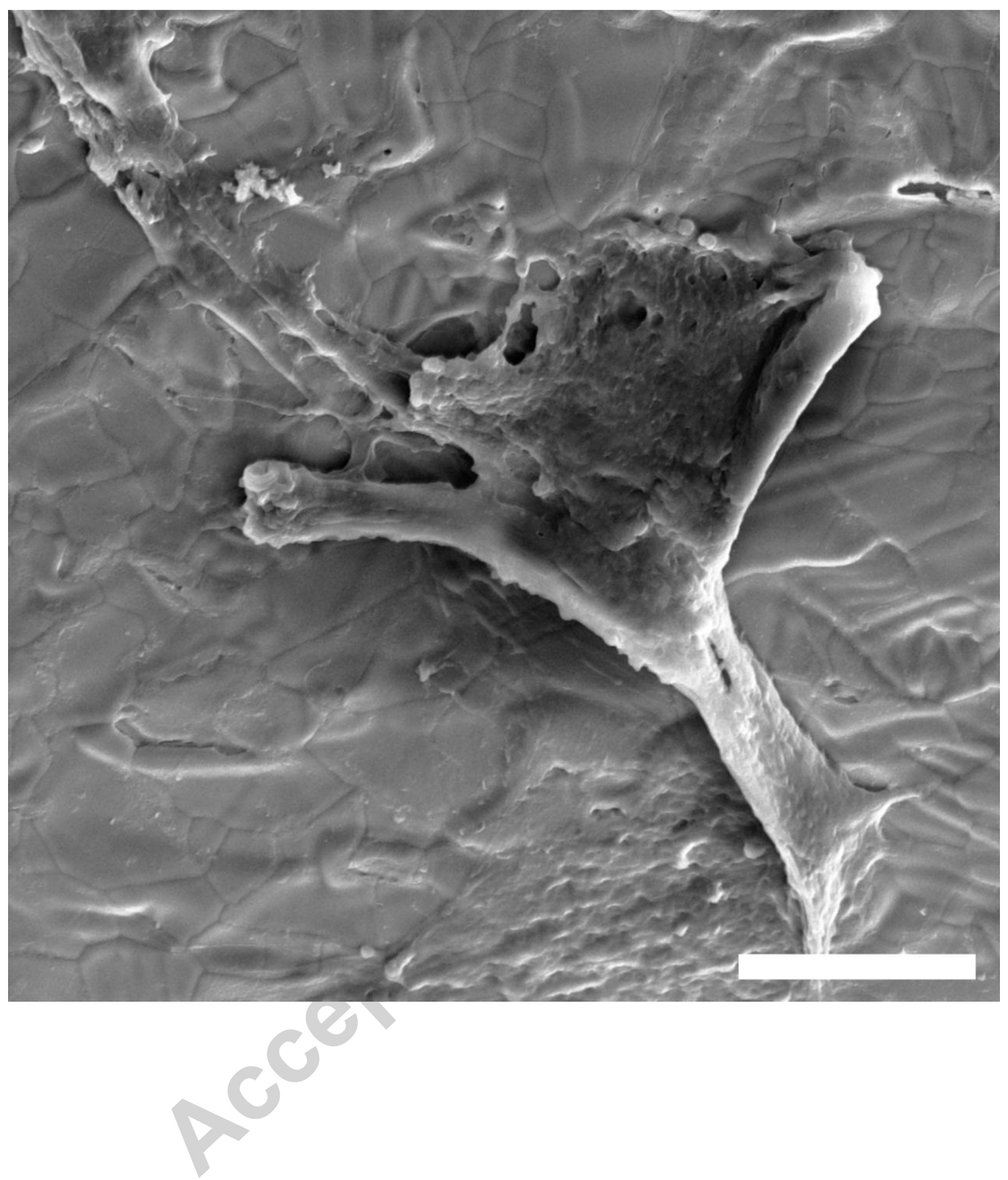


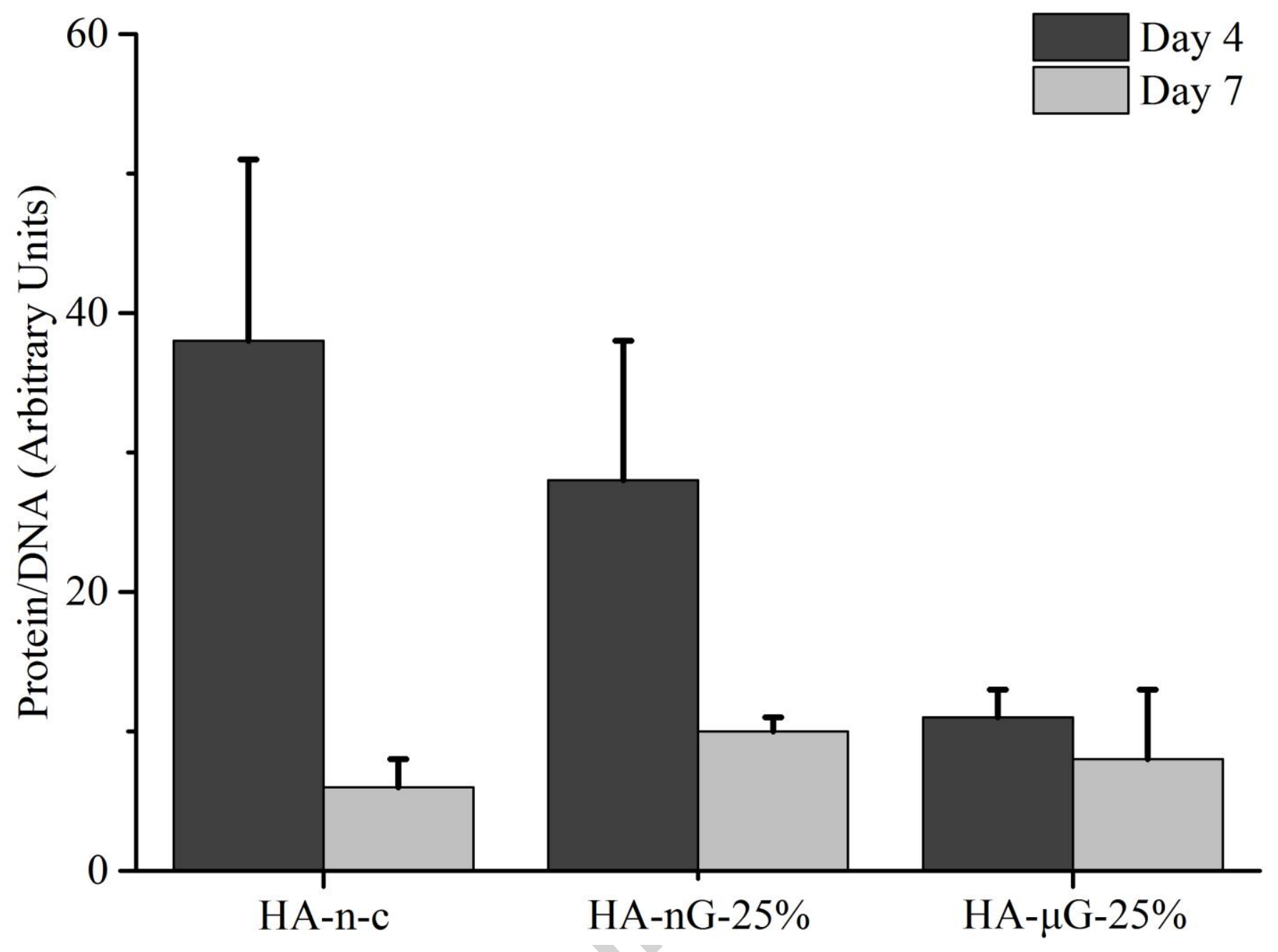



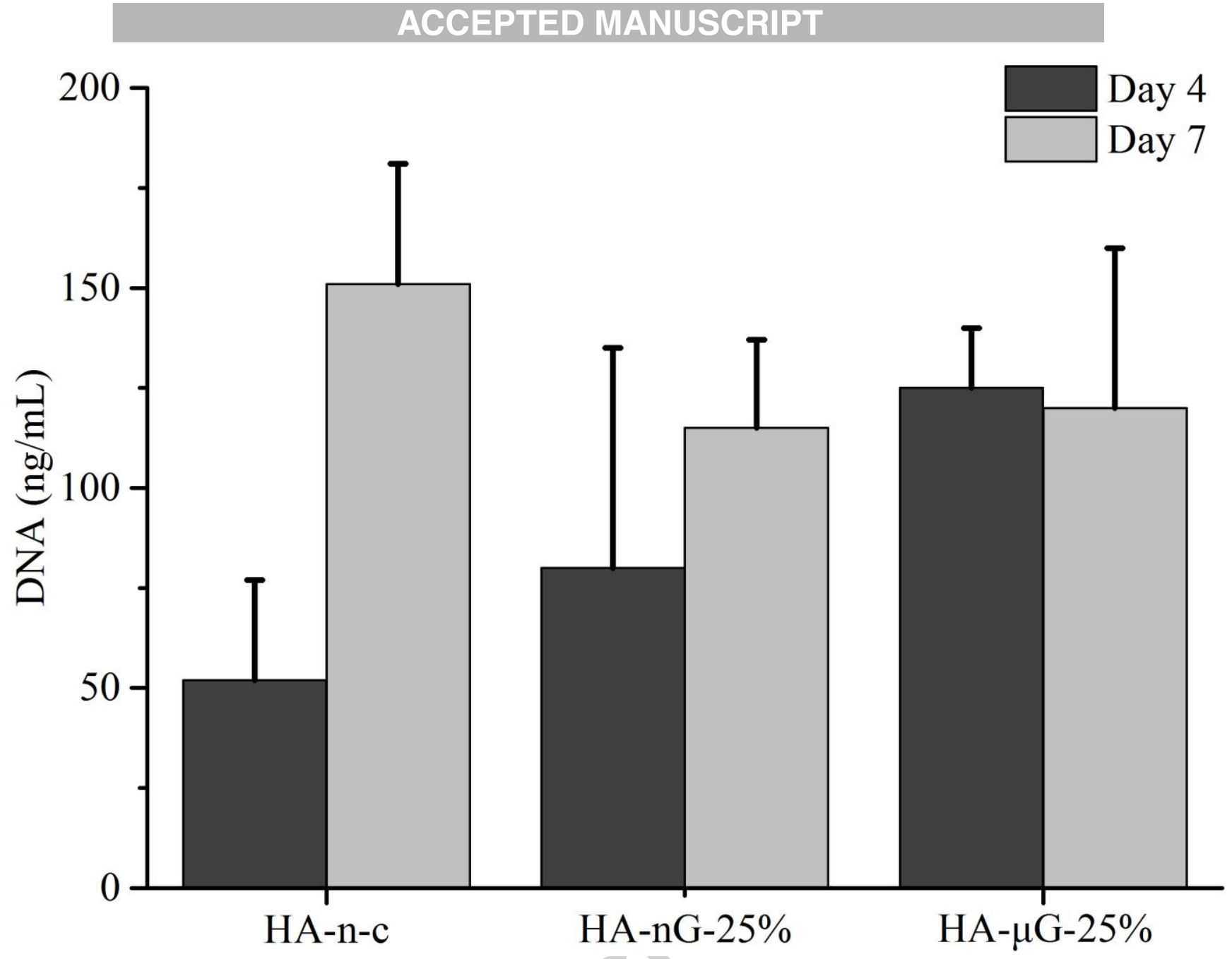

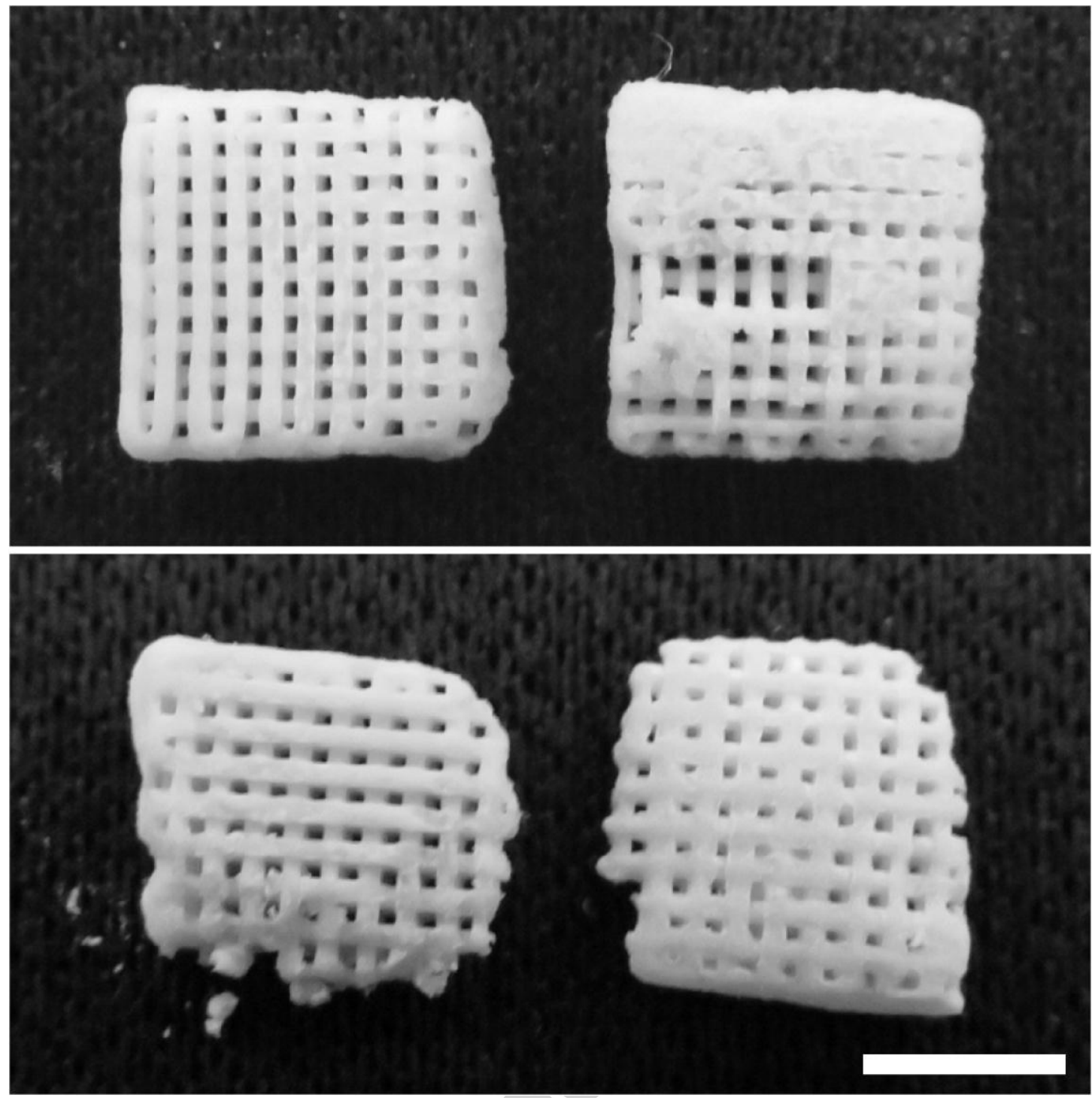

$(3)$ 

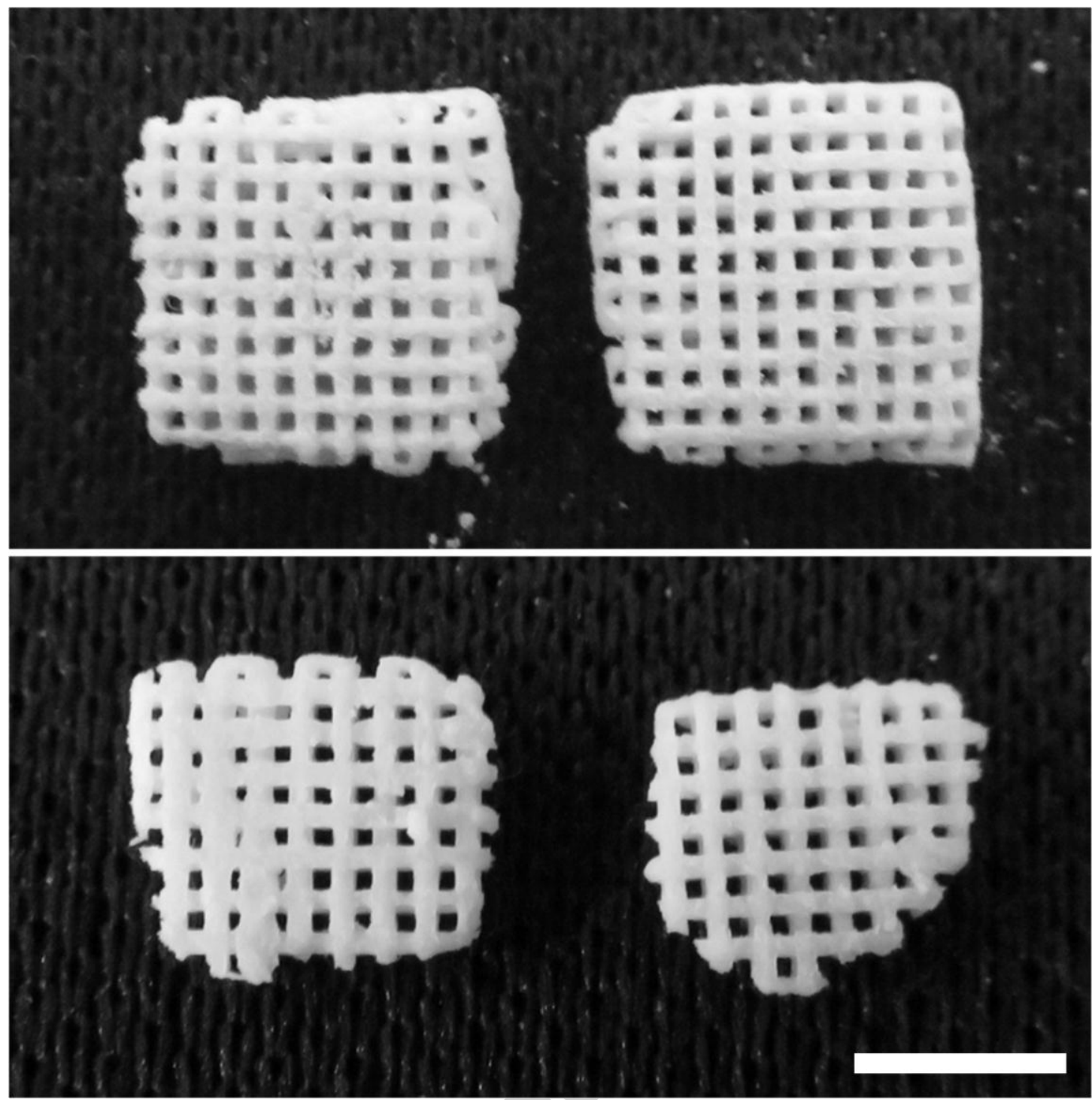
ACCEPTED MANUSCRIPT
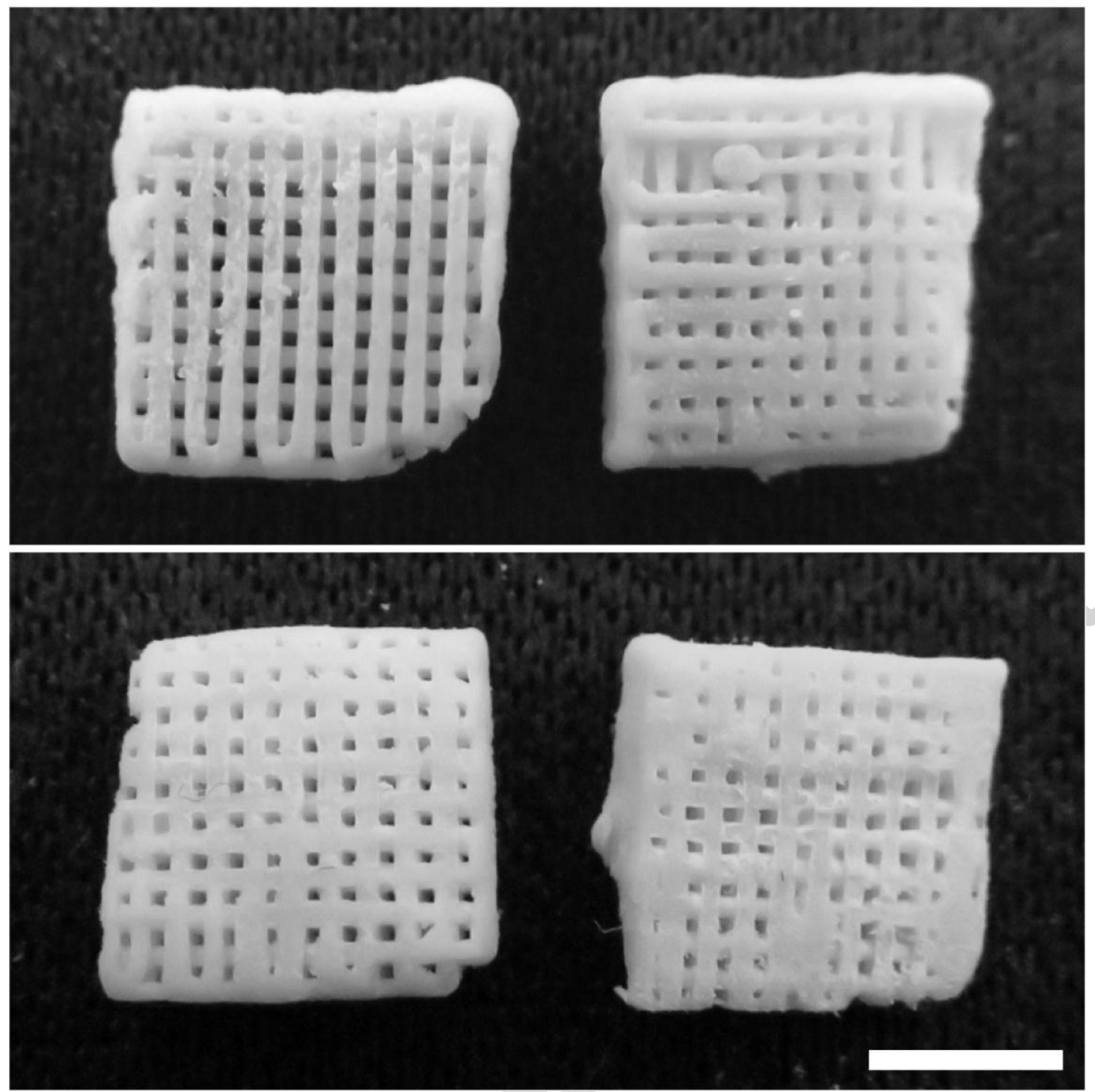

$(4)$

2

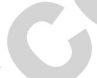

( $)$ 


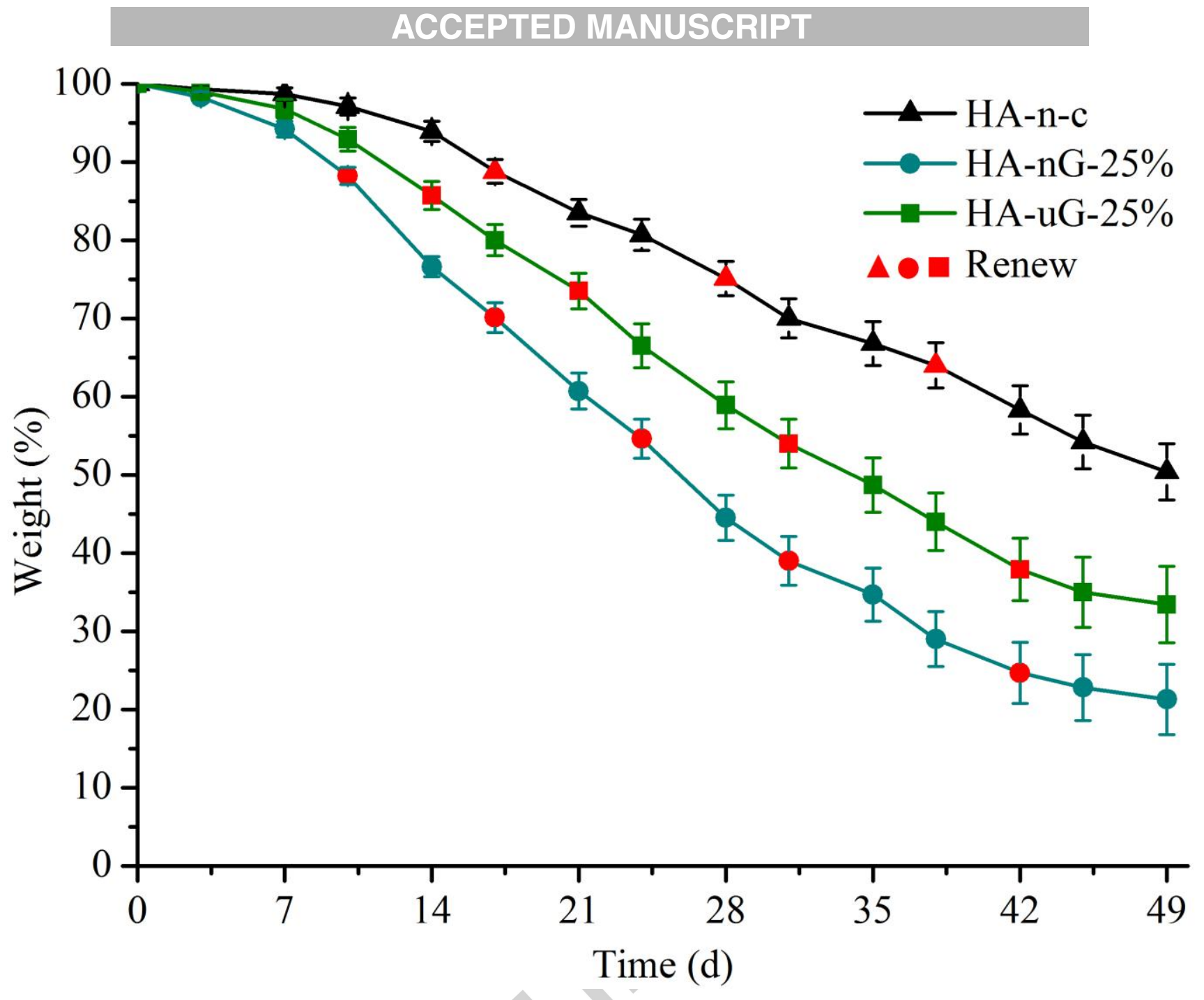




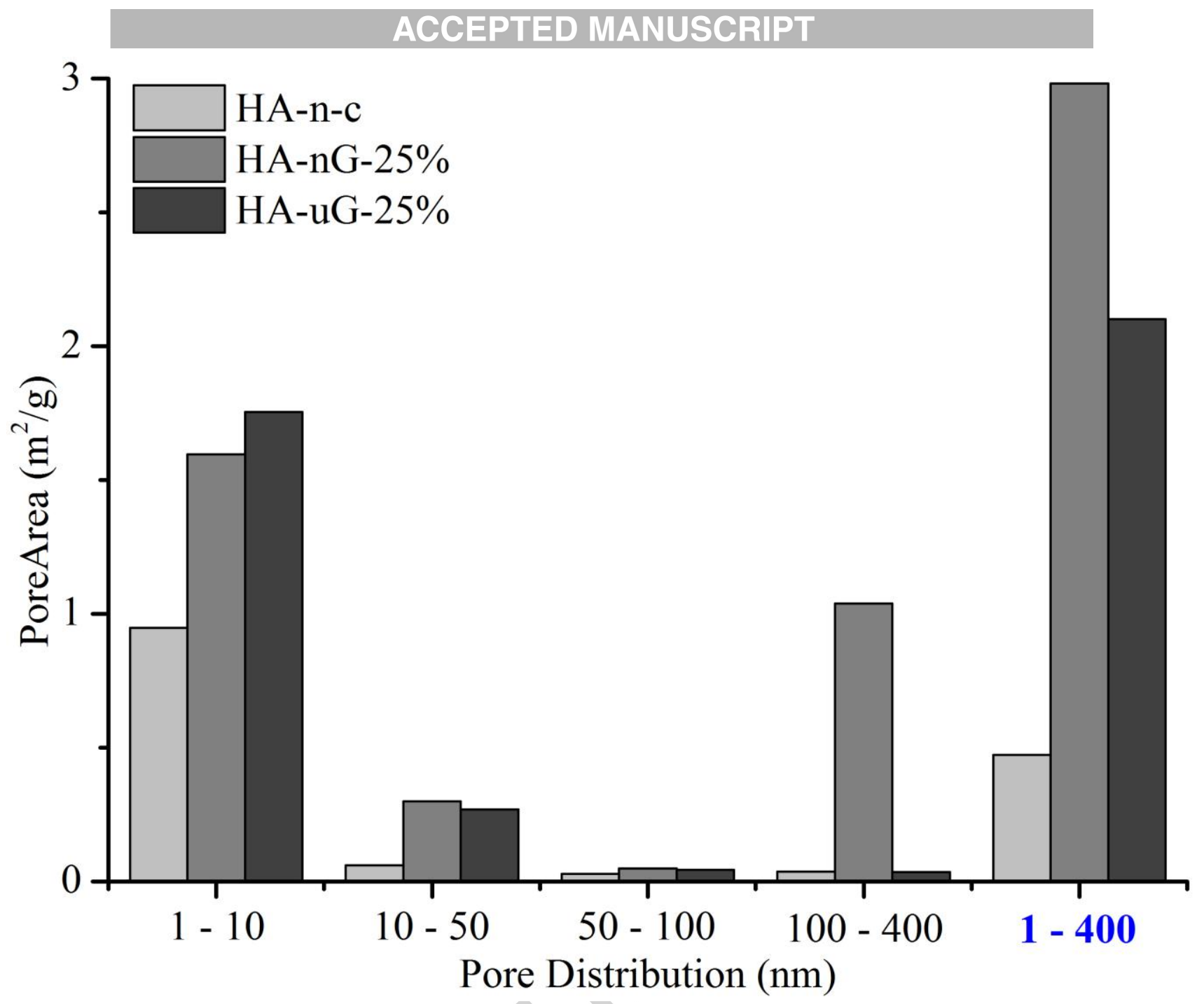



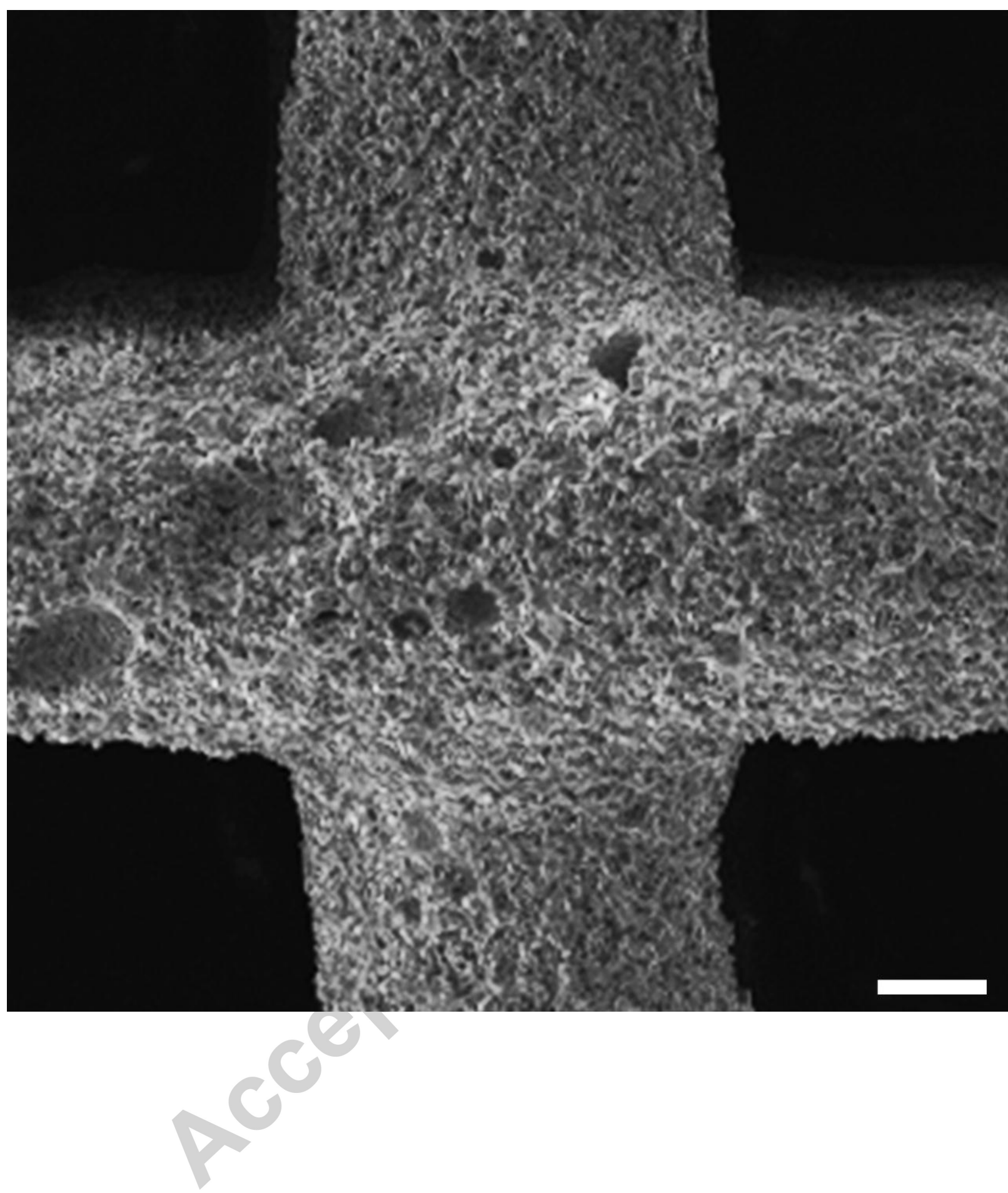


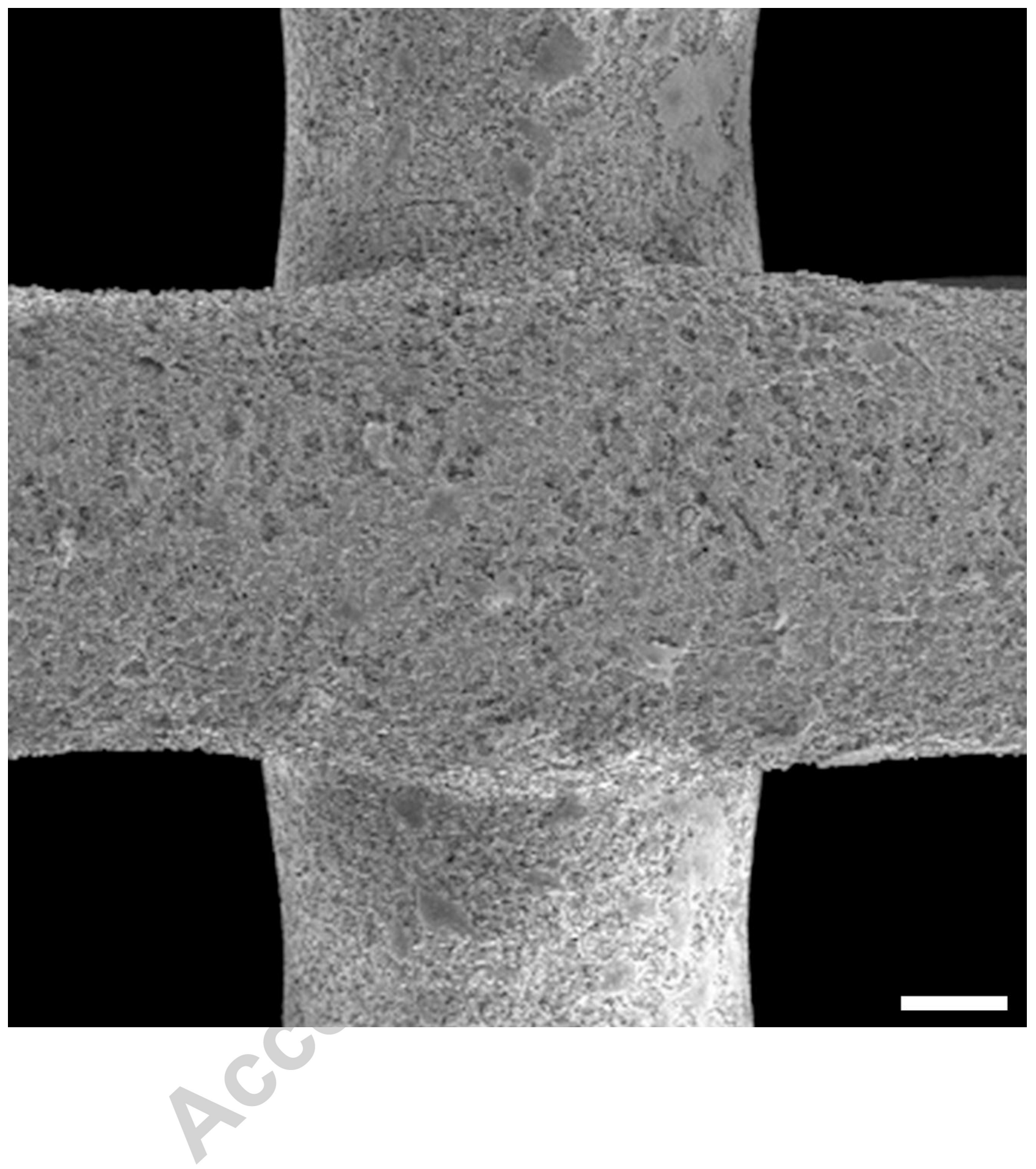




\section{ACCEPTED MANUSCRIPT}

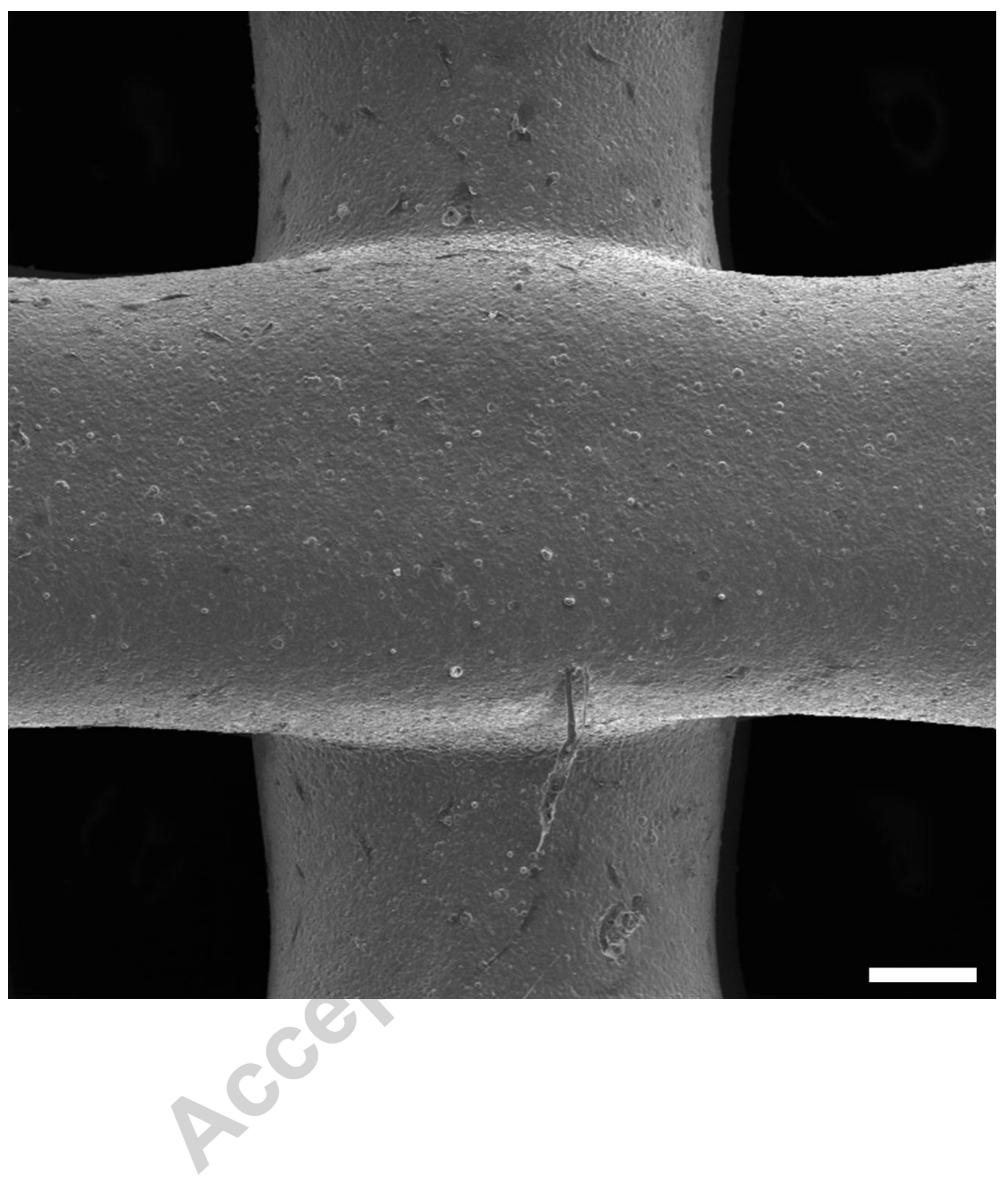




\section{ACCEPTED MANUSCRIPT}

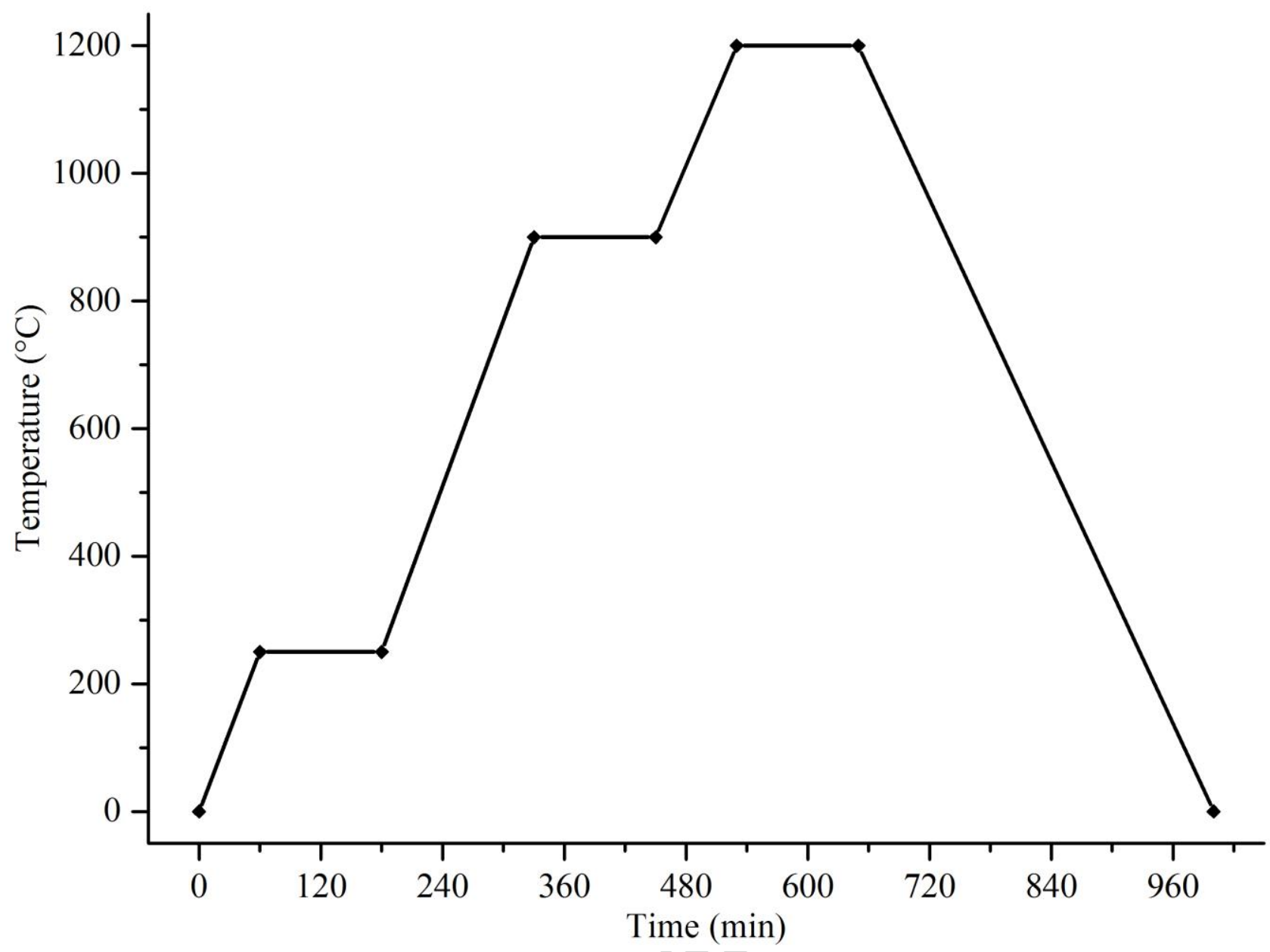




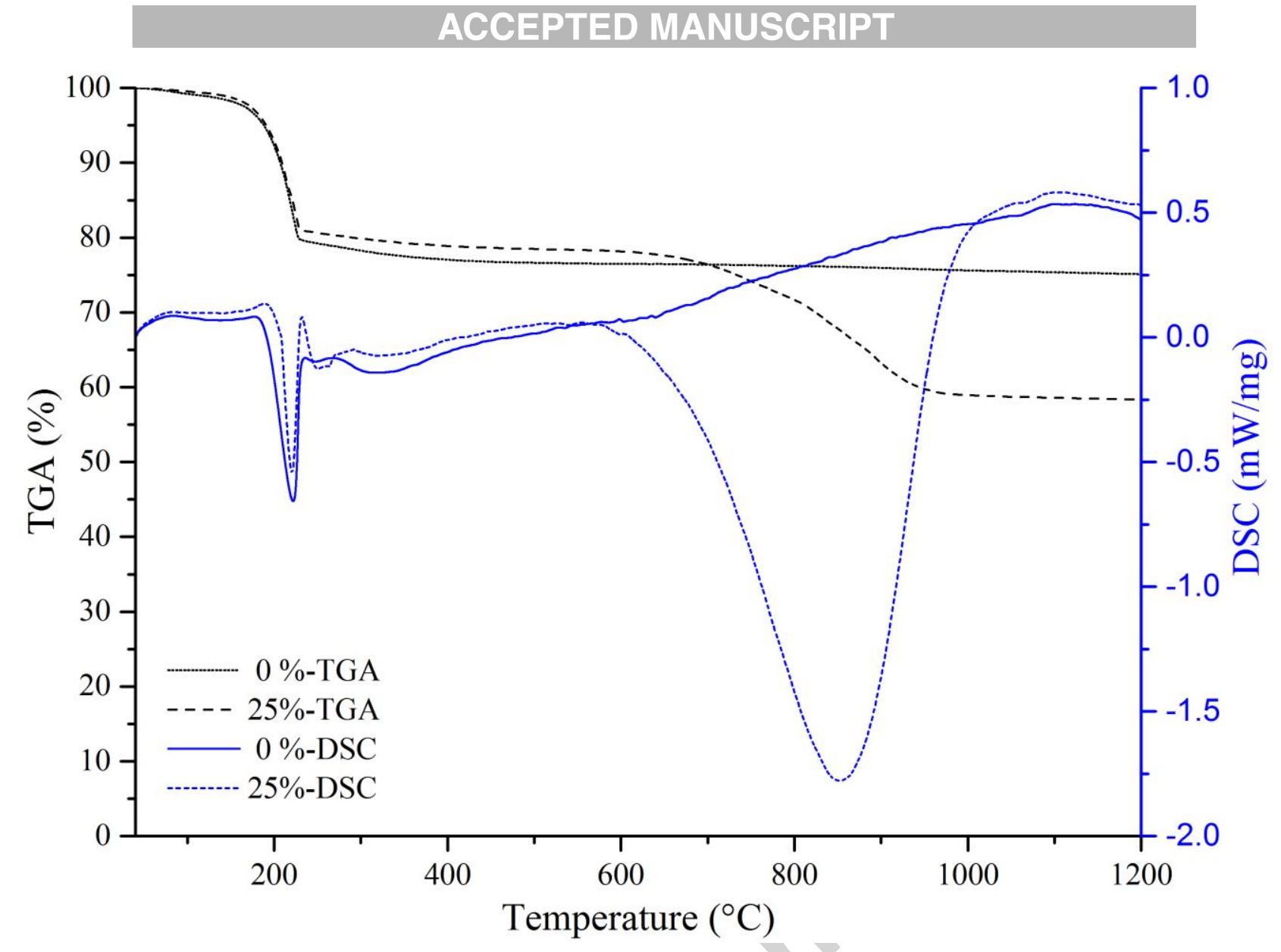




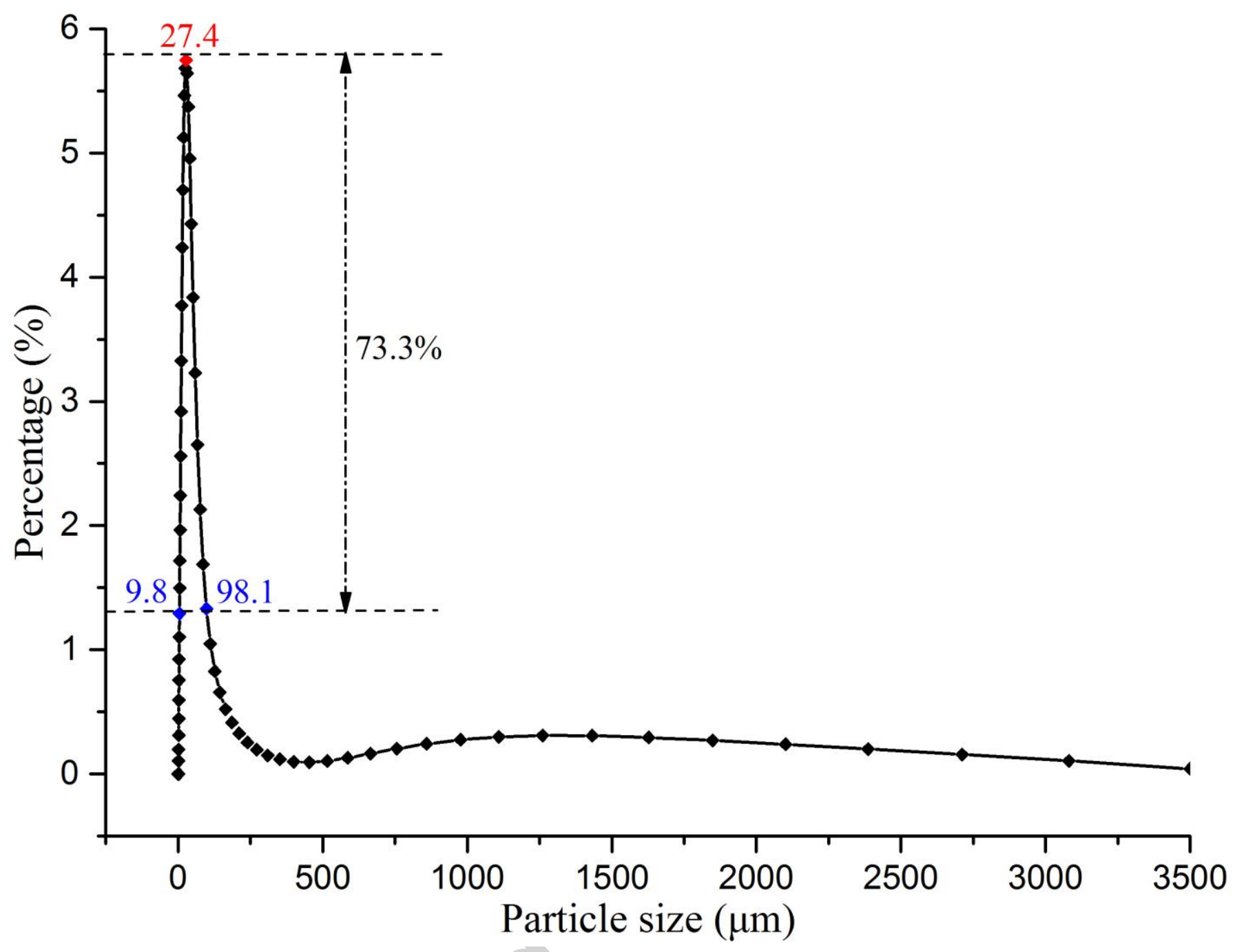




\section{ACCEPTED MANUSCRIPT}

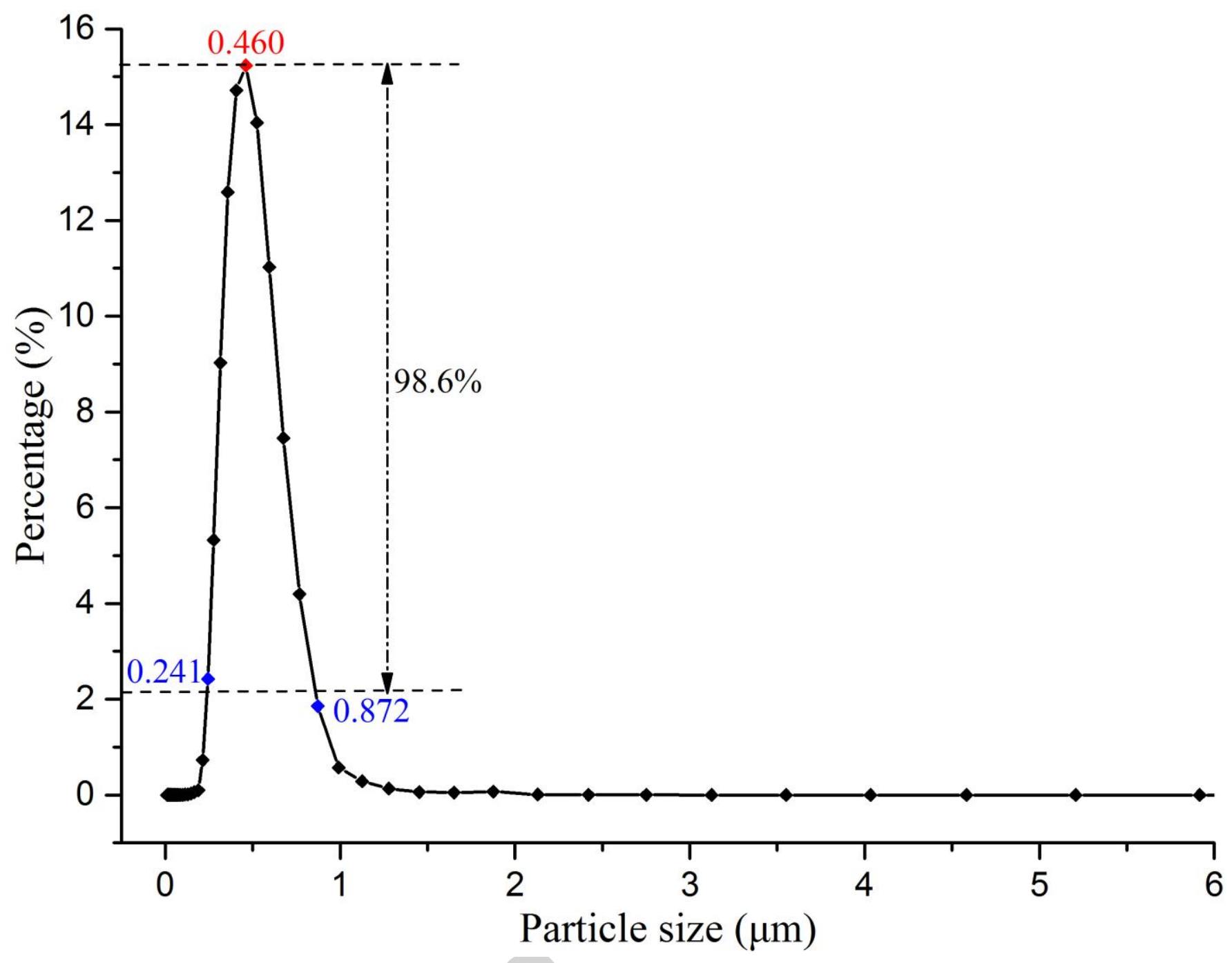

